\title{
Bibenzyls and bisbybenzyls of bryophytic origin as promising source of novel therapeutics: pharmacology, synthesis and structure-activity
}

\author{
Samapika Nandy ${ }^{1} \cdot$ Abhijit Dey $^{2}$
}

Received: 27 August 2019 / Accepted: 30 March 2020 / Published online: 15 August 2020

(C) Springer Nature Switzerland AG 2020

\begin{abstract}
Background The amphibian, non-vascular, gametophyte-dominant, bio-indicator class, bryophytes; with their wide ranges of habitat have attained importance due to their promising medicinal attributions and therapeutic role; mostly aided by presence of aromatic bibenzyl and bisbybenzyl class of compounds. Bibenzyls are steroidal ethane derivatives, resembling the structural moiety of bioactive dihydro-stilbenoids or iso-quinoline alkaloids. These stress triggered secondary metabolites are the byproducts of the flavonoid biosynthetic pathway. Different classes of bryophytes (Bryophyta, Marchantiophyta and Anthocerotophyta) possess different subtypes of bibenzyls and dimeric bisbibenzyls. Among the liverwort, hornwort and mosses, former one is mostly enriched with bibenzyl type constituents as per the extensive study conducted for phytochemical deposit. Considering macrocyclic and acyclic group of bibenzyls and bisbybenzyls, generally marchantin type compounds are reported vividly for significant biological activity that includes neuro-nephro-cardio-protection besides anti-allergic, anti-microbial, anti-apoptotic and cytotoxic activities studied on in-vitro and in-vivo models or on cell lines.

Result The critical analysis of reported chemical and pharmaceutical attributions of bibenzyls and bis-bibenzyls yielded detailed report on this compound class along with their application, mode of action, natural source, techniques of synthesis, extraction procedure, isolation and characterization. Further, the structure activity relationship studies and bioactivity of bibenzyls derived from non-bryophytic origin were also summarized.

Conclusion This review encompasses prospective biological application of botanical reservoir of this primarily ignored, primeval land plant group where recent technical advances has paved the way for qualitative and quantitative isolation and estimation of novel compounds as well as marker components to study their impact on environment, as bio-control agents and as key leads in future drug designing.
\end{abstract}

Keywords bibenzyls $\cdot$ bisbybenzyls $\cdot$ marchantin $\cdot$ riccardin $\cdot$ anti-apoptotic $\cdot$ anticancer

\section{Introduction}

Bryophytes, the "amphibians of the plant kingdom", are taxonomically placed between thallophytes and pteridophytes and subdivided into Bryophyta or mosses ( 14,000 species),

Abhijit Dey

abhijit.dbs@presiuniv.ac.in

Samapika Nandy

samapika.nandy25@gmail.com

1 Research Scholar, Department of Life Sciences, Presidency University, Kolkata 700073, India

2 Department of Life Sciences, Presidency University, Kolkata 700073, India
Marchantiophyta or liverworts ( 6000 species) and Anthocerotophyta or hornworts ( $\sim 300$ species) [1]. According to paleo-ontological dating, these are the oldest terrestrial plant group, originated 440-450 million years ago [2] These small-sized plants are photosynthetic, non-vascular, mostly un-lignified with heteromorphic alternation of generation and are highly susceptible to desiccation [3]. The difficulty in collection, identification and subsequent molecular analyses has rendered this plant group unexplored for decades in the field of pharmaco-nutraceutical studies [4]. Recent advances in quality control techniques and molecular data mining have widened the identification of phytochemical and pharmacological attributes of different species of bryophytes throughout the globe. Exposure to biotic and abiotic stresses often triggers production of biologically active, toxic, 
allelopathic secondary metabolites which shield them against microbes, insects, molluscs, mammals, heavy metals and ultraviolet radiation $[5,6]$. Varieties of terpenoids include unstable dialdehydes and hemiacetals, flavonoids, many highly unsaturated fatty acids, alkanones and aromatic compounds such as bibenzyls [7-11] and bis-bibenzyls, acetogenins, phytosterols and flavonoid glycosides were isolated or detected and subjected to hemisynthesis or total synthesis for further structural and functional elucidation [12]. This review comprises of the phyto-therapeutic bioactivities of one of the major phytochemicals harvested from bryophytes, the bibenzyls and bisbibenzyls $[8,13,14]$. Besides their characteristic odour and pungency, these compounds and their derivatives impart characteristic properties viz. allergic dermatitis, antimicrobial, anti-feedant, insecticidal, nematocidal, piscicidal, anti-radical, anti-thrombin, cytotoxic, neuro-nephro-cardioprotective properties and also possess inhibitory activities against 5lipoxygenase, calmodulin, hyaluronidase, cyclooxygenase, DNA polymerase $\beta, \alpha$-glucosidase, calcium and tubulin polymerization [15-24]. Some bryophytes also function as inhibitor of plant growth and mimicked structural moiety of sex pheromones $[25,26]$. Liverworts are mostly enriched in lipophilic mono-, sesqui- and di-terpenoid content with typical bibenzyls and bis-bibenzyls which have also been isolated from different plant families. Bibenzyls are colourless solid ethane derivatives originated via flavonoid biosynthetic pathway. Different subtypes of bibenzyls and bisbibenzyls are present in different bryophyte species [27, 28] viz.cyclic (Marchantia emarginata Reinw., Blume \& Nees); macrocyclic (Asterella angusta (Steph.) Pandé, K.P. Srivast. \& Sultan Khan, Blasia pusilla L., Dumortiera augustan L.); chlorinated (Riccardia marginata (Colenso) Pearson); polychlorinated (Riccardia polyclada (Mitt.) Hässel); prenylated (Radula perrottetii Gottsche ex Steph.), cinnamoylated (Polytrichum pallidisetum Funck); geranylated (Radula kojana Steph.); hydroxybenzylated (Radula complnata (L) Dumort) [29-32] etc. Among all these classes and subclasses marchantin type of macrocyclic bis-bibenzyls have been reported to possess very promising bioactivities [33]. Till date almost more than 60 macrocyclic and acyclic bis-bibenzyls have been isolated and chemically synthesized to elucidate their structure, pharmacology, agricultural consortium and applications as nutraceuticals or cosmetics [34-36].

\section{Methodology}

Reliable and popular international scientific databases such as PubMed, Scopus, Science Direct, Research Gate, Google Scholar, etc. were searched using the search strings such as "bioactivity of bibenzyls", "anti-cancer bryophytes", "chemical composition of bryophytes", "bibenzyl cytotoxicity", "bibenzyl structures" and other relevant keywords to retrieve a number of citations related to chemical and pharmaceutical attributions of bibenzyls and bis-bibenzyls. The retrieved citations were further cross-referenced and a total of 200 relevant references are reported here to depict the entire research related to many natural and synthetic bibenzyls and bisbibenzyls. Extensive research work on bryophytes from the group of scientists led by Professor Y. Asakawa (faculty of Tokushima Bunri University) is widely described in this review. Figure 1 stands for the pictorial presentation of the habits of some bryophytes taken in their wild environment. Images $\mathrm{a}, \mathrm{b}$ and $\mathrm{c}$ were obtained from Wikimedia Commons under the GNU Free Documentation License (http://en.wikipedia.org/wiki/GNU_Free_Documentation License), Image D was taken from similar source and licensed under the Creative Commons CC0 1.0 Universal Public Domain Dedication (https://creative commons.org/publicdomain/zero/1.0/deed.en) and images numbered as g-h were included from our personal collection (photographed from Eastern Himalaya by the corresponding author). Further, the mode of action of bibenzyls and bis(bi)benzyls corresponding to their source bryophytes are extensively presented in Table 1 and bibenzyls derived from non-bryophytic origin, with corresponding bioactivity, are tabulated in Table 2 . The molecular structures of these compounds are presented in Figure 2. Scientific names of the bryophytes were further validated from www.tropicos.com and chemical structures and molecular formula were retrieved from Pub Chem (https://pubchem.ncbi.nlm.nih.gov/)

\section{Bioactivity of bibenzyls and bis(bi)benzyl}

Bibenzyl and their dimeric form bis(bi)benzyls are the allelopathic protectant molecules reported to delay, bypass or prevent herbivory, pathogenesis, drought induced damage or untimely freezing under harsh unfavourable environmental stresses [3]. These bryophyte- specific macrocyclic compounds have demonstrated an array of bioactive properties such as anti-cancer, anti-microbial, anti-oxidant, LXR $\alpha$ activating, HIV preventive, enzyme (cyclooxygenase, lipoxygenase, tyrosinase, calmodulin) modulating and microtubule polymerizing activities [37-41]. Like other secondary metabolites isolated from higher group of plants, these compounds were also reported for some therapeutic application often accompanied with potent radical scavenging, anti-microbial and proapoptotic activities [14, 42, 43].There are reports of many bibenzyls and derivatives which lack any pharmacological data till date. 3,3'-dimethoxy-4-hydroxybibenzyl isolated from Plagiochila species [44]. 3,5 dihydroxy-2-(3-methyl-2_butenyl) bibenzyl, 3,5-dihydroxy-6-carbomethoxy- 
Fig. 1 Habits of few bioactive bryophytes; a. Bazzania trilobata, b. Blasia pusilla c. Radula complanata d. Riccardia multifida, e. Marchantia paleacea, f. M. polymorpha, g. M.papillata, h. Dumortiera hirsuta

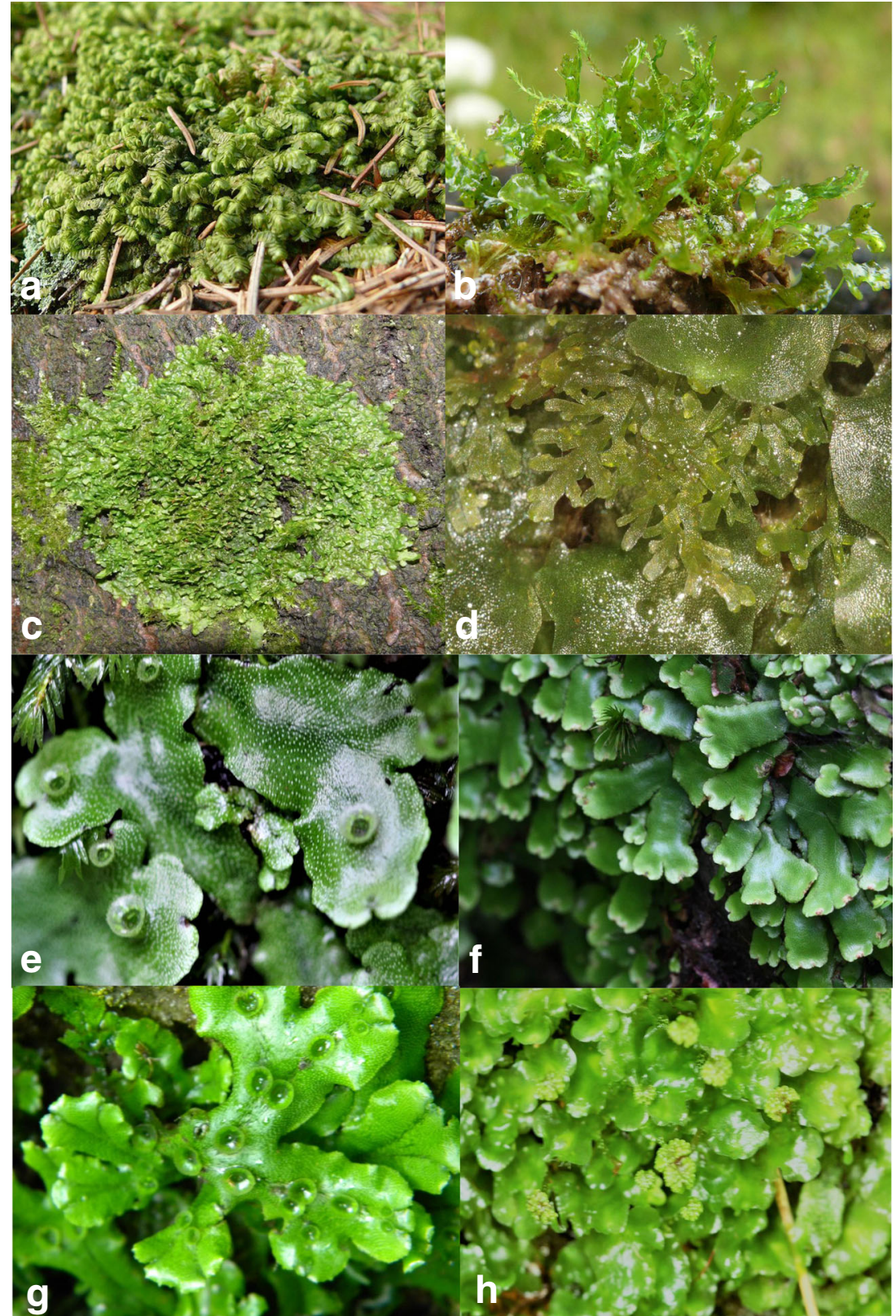

2-(3-methyl-2-butenyl) bibenzyl [13], 3,3'dimethoxy-4,5methylenedioxy-4, - hydroxybibenzy 1 , 3,4,3',4'dimethylene dioxybibenzyl, 3,3'dimethoxy+methylene dioxybibenzyl and 3,3'dihydroxy4,5,4', Sdimethylene dioxybibenzyl isolated from Frullania species, angustatin A from Asterella angusta [45], cavicularin isolated from Cavicularia densa Steph [46], isoplagiochins E, F, G, ptychantols A-C, isoperrotetin A [47] were reported with different medicinal properties. However, the following section depicts the medicinal efficacy of selected naturally derived and chemically synthesized bibenzyls and their derivatives, along with their sources and details of experimental methodologies.

\section{Asterelin A, Asterelin B}

\section{Anti-fungal activity}

These dibenzofuran bisbibenzyls were isolated from the liverwort Asterella angusta (Steph.) Pandé, K.P. Srivast. \& Sultan Khan by bioactivity-guided fractionation and the extract was evaluated against the pathogenic fungi Candida albicans through bioautographic and broth microdilution assays; using fluconazole as standard drug. The minimum inhibitory concentration (MIC) value ranged from 16 to $512 \mu \mathrm{g} / \mathrm{ml}$. The structures of the compounds were elucidated by $1 \mathrm{D}$ and 2Dnuclear magnetic resonance (NMR), mass spectroscopy (MS) and X-ray crystallographic diffraction (CD) analyses [48]. 


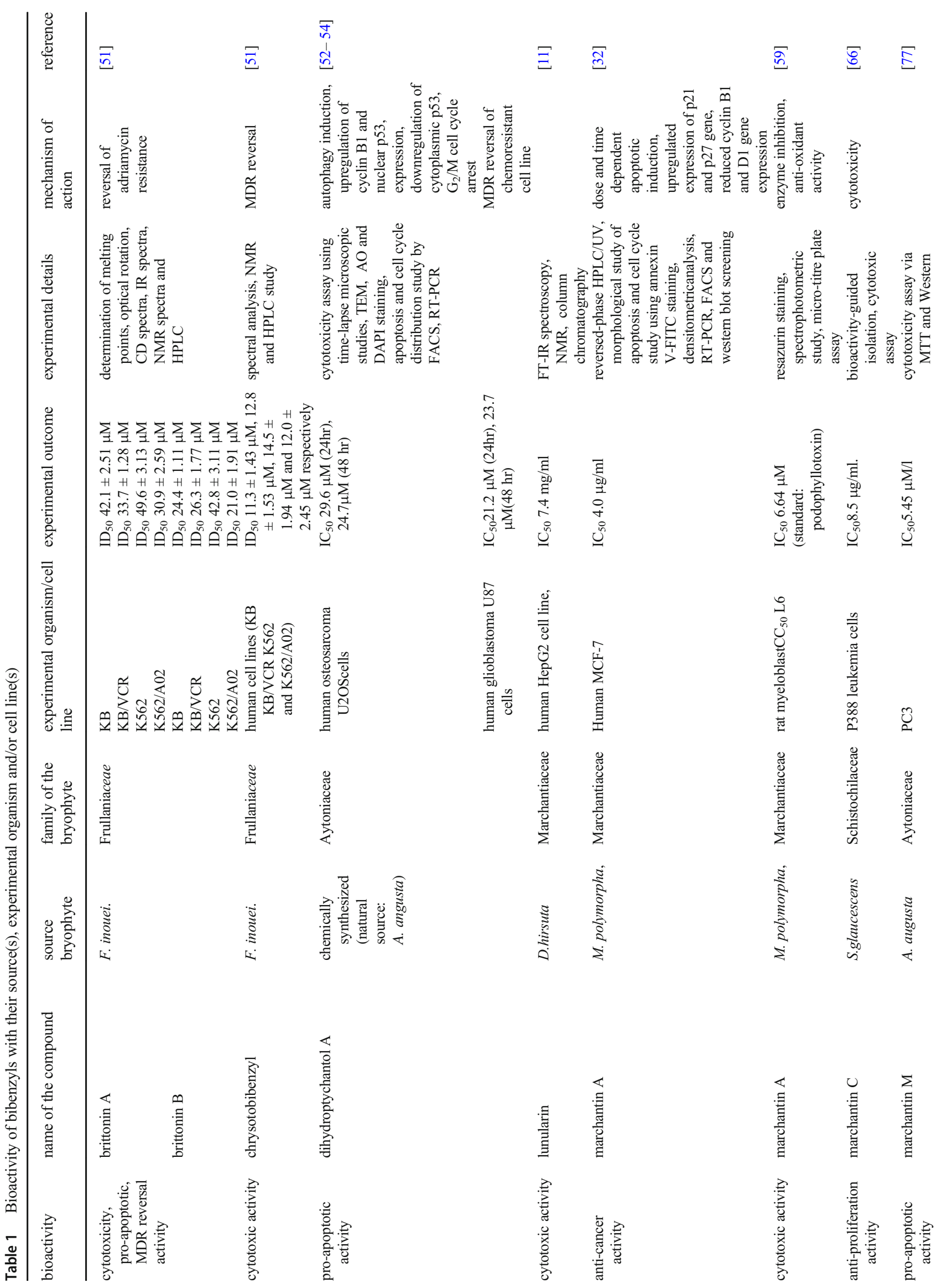




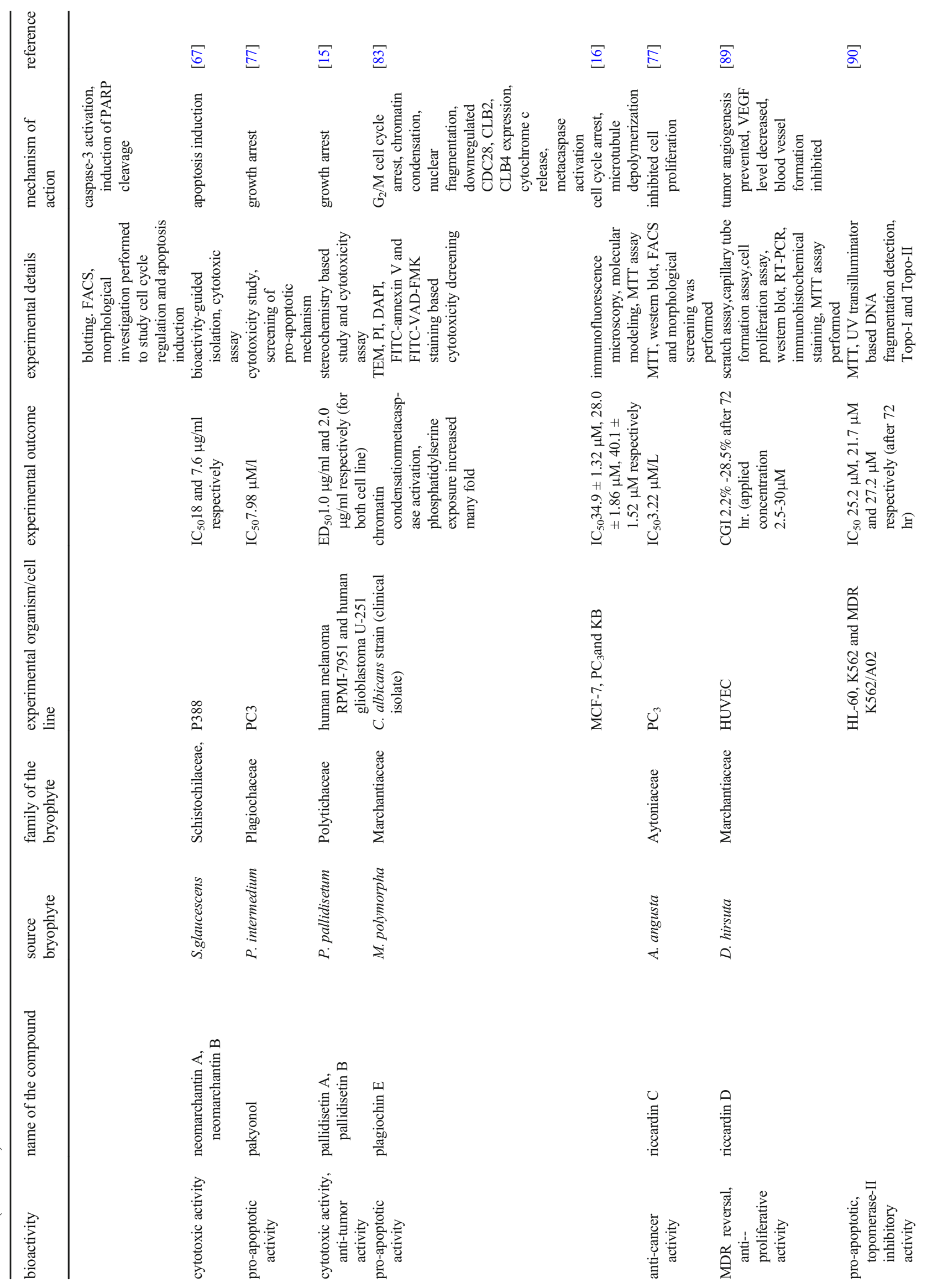




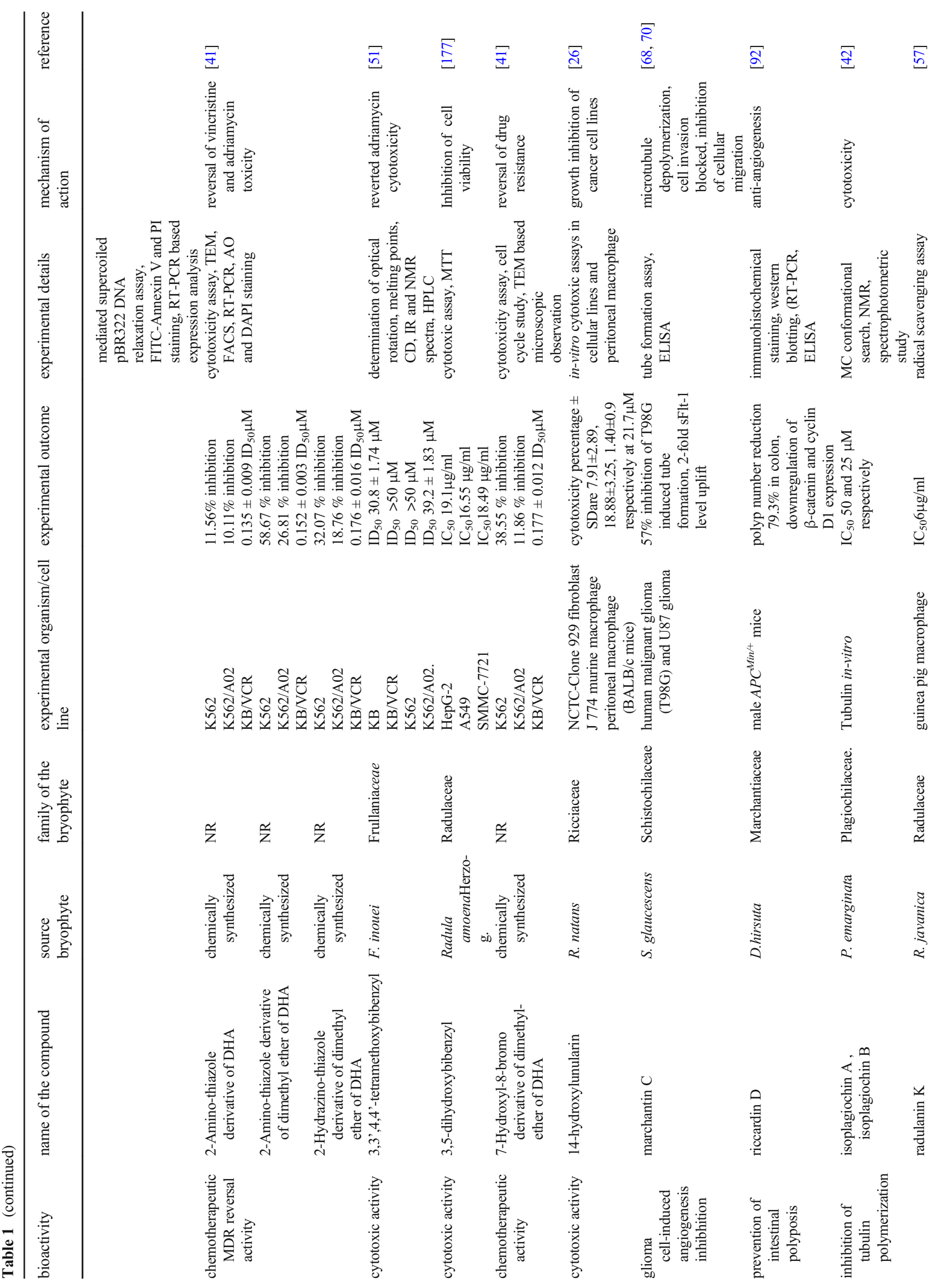




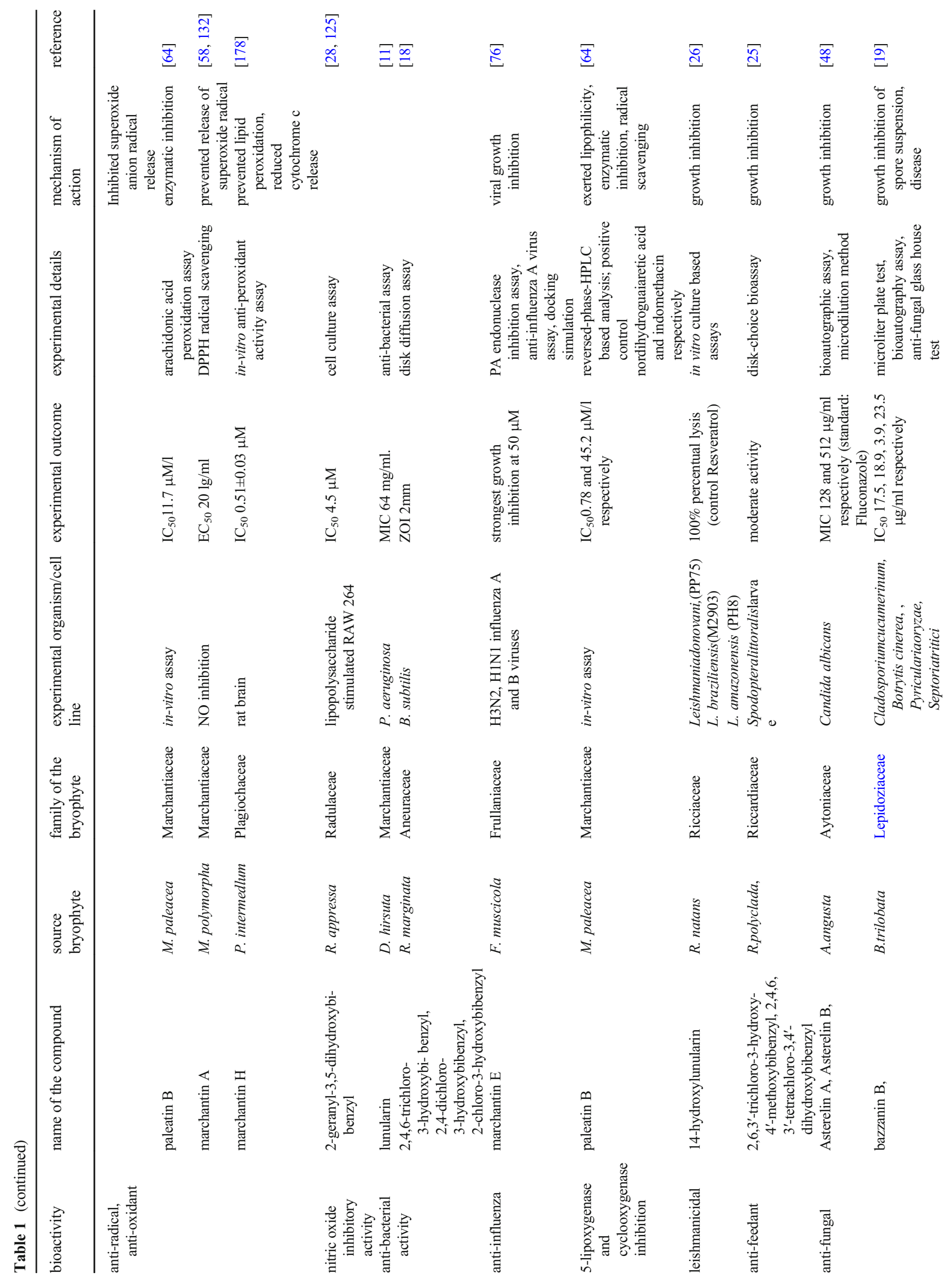




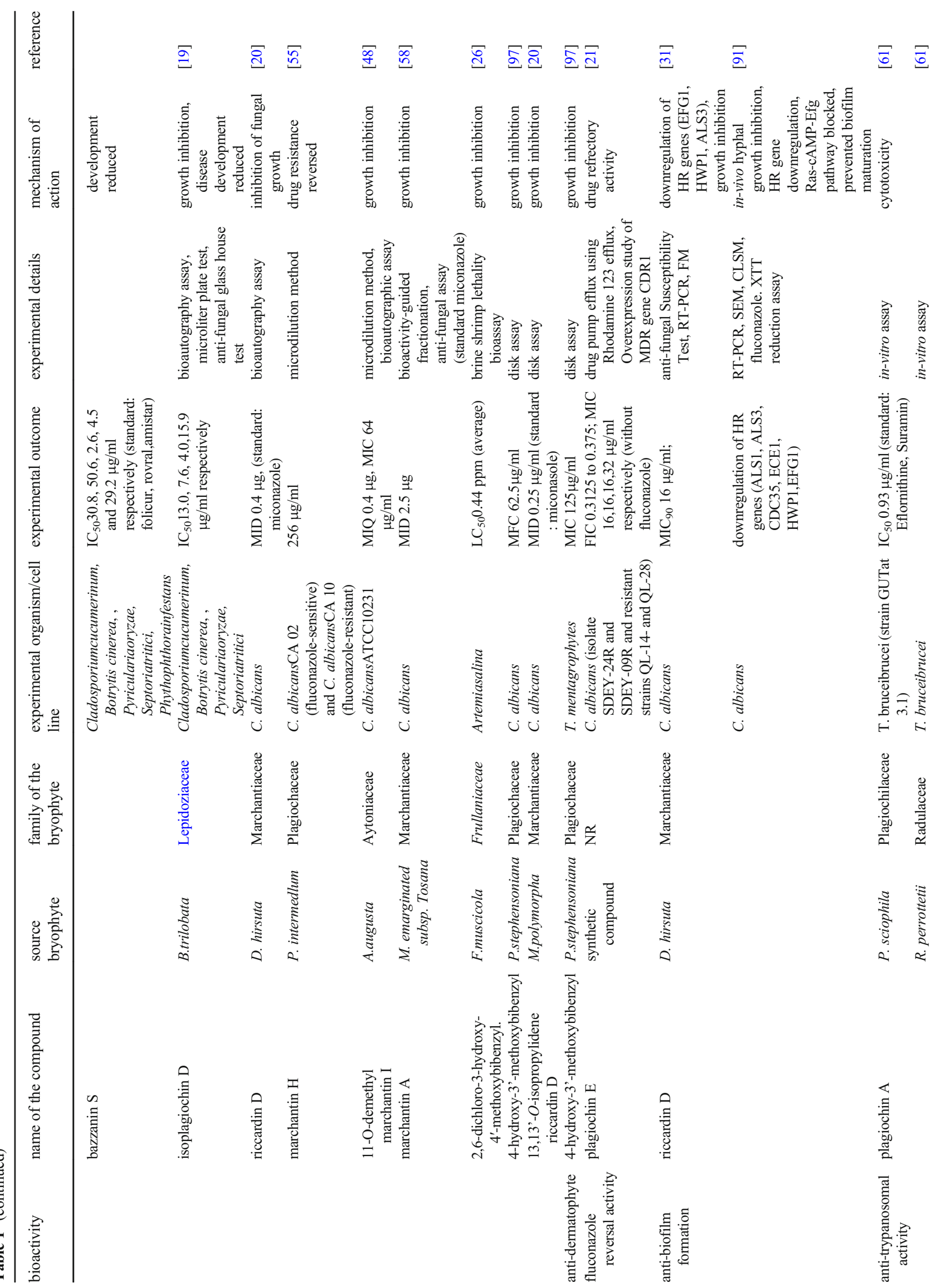




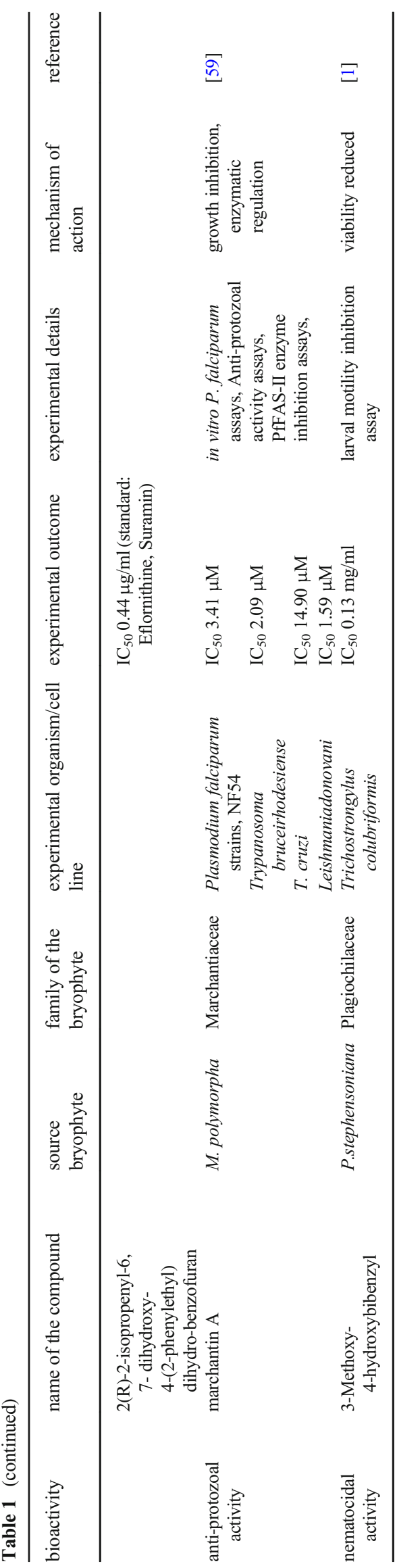

Bazzanin B, Bazzanin S

\section{Anti-fungal activity}

The bio-autography on thin layer chromatographic (TLC) assay-guided fractionation was employed to isolate bisbibenzyls bazzanin B $\left(6^{\prime}, 8^{\prime}\right.$-dichloroisoplagiochin C) and bazzanin $\mathrm{S}$ (6'-chloroisoplagiochin $\mathrm{D}$ ) from dichloromethane and methanol extracts and also from ethyl acetate-soluble fraction of alcoholic extract of the airdried liverwort Bazzania trilobata (L.) Gray. These extract showed significant colony inhibiting activity against five phyto-pathogenic fungi detected by microtiter plate assay [49]. The structures of isolated bibenzyls were confirmed by extensive NMR spectral analysis [19]. Bazzanin S has formed a larger zone of inhibition (ZOI) compared to its per-methylated derivative when acted against Cladosporium cucumerinum, a fungal plant pathogen. The activity was tentatively attributed to the presence of a free $\mathrm{OH}$ - group which may be responsible for contributing this inhibitory activity. It has shown inhibitory activity against Pyricularia oryzae with half maximal inhibitory concentration $\left(\mathrm{IC}_{50}\right)$ values of $3.9,4.0$ and $2.6 \mu \mathrm{g} / \mathrm{ml}$ whereas $\mathrm{IC}_{50}$ values for Septoria tritici were observed as 23.5, 15.9 and $4.5 \mu \mathrm{g} / \mathrm{ml}$. Activity of bazzanin $\mathrm{S}$ and bazzanin B against $C$. cucumerinum and Botrytis cinerea were comparable with standard drugs like tebuconazole, iprodione and azoxystrobin. However, all isomers of bazzazins A-S are reported from B. trilobata [47]

\section{Brittonin A, Brittonin B}

\section{Anti-proliferative activity}

These methoxylated bibenzyls, isolated from the liverwort Frullania inouei S. Hatt., showed profound cytotoxicity and significant anti-proliferative activity with $50 \%$ infectious dose $\left(\mathrm{ID}_{50}\right)$ values ranging from 11.3 to $49.6 \mu \mathrm{M}$ when tested on human tumor cell lines viz. KB, KB/VCR, $\mathrm{K} 562$ or K562/A02. These compounds were also reported from Frullania brittoniae subsp. truncatifolia A. Evans [50]. These compounds have exhibited multi-drug resistance (MDR) with reversal fold values ranging from 3.19 to $10.91(5 \mu \mathrm{M})$ for vincristine-resistant $\mathrm{KB} / \mathrm{VCR}$ cell lines and 4.40 to $8.26(5 \mu \mathrm{M})$ for adriamycin-resistant K562/A02 cell lines, respectively. Structure elucidation was accomplished through NMR assay, time-dependent density functional theory (TDDFT)-CD calculations and single-crystal X-ray diffraction measurements [51]. Molecular structures of these phytochemicals were 


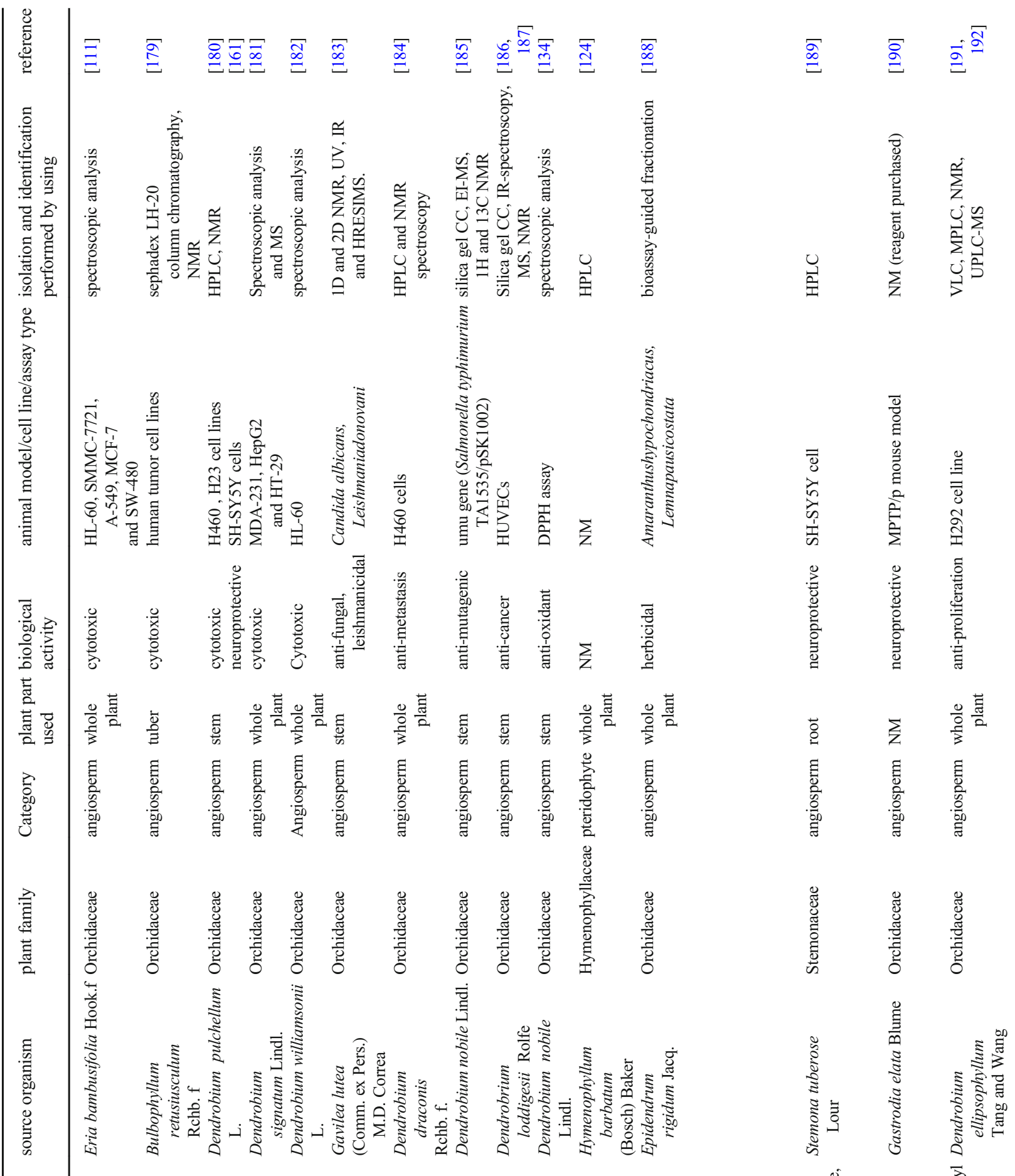




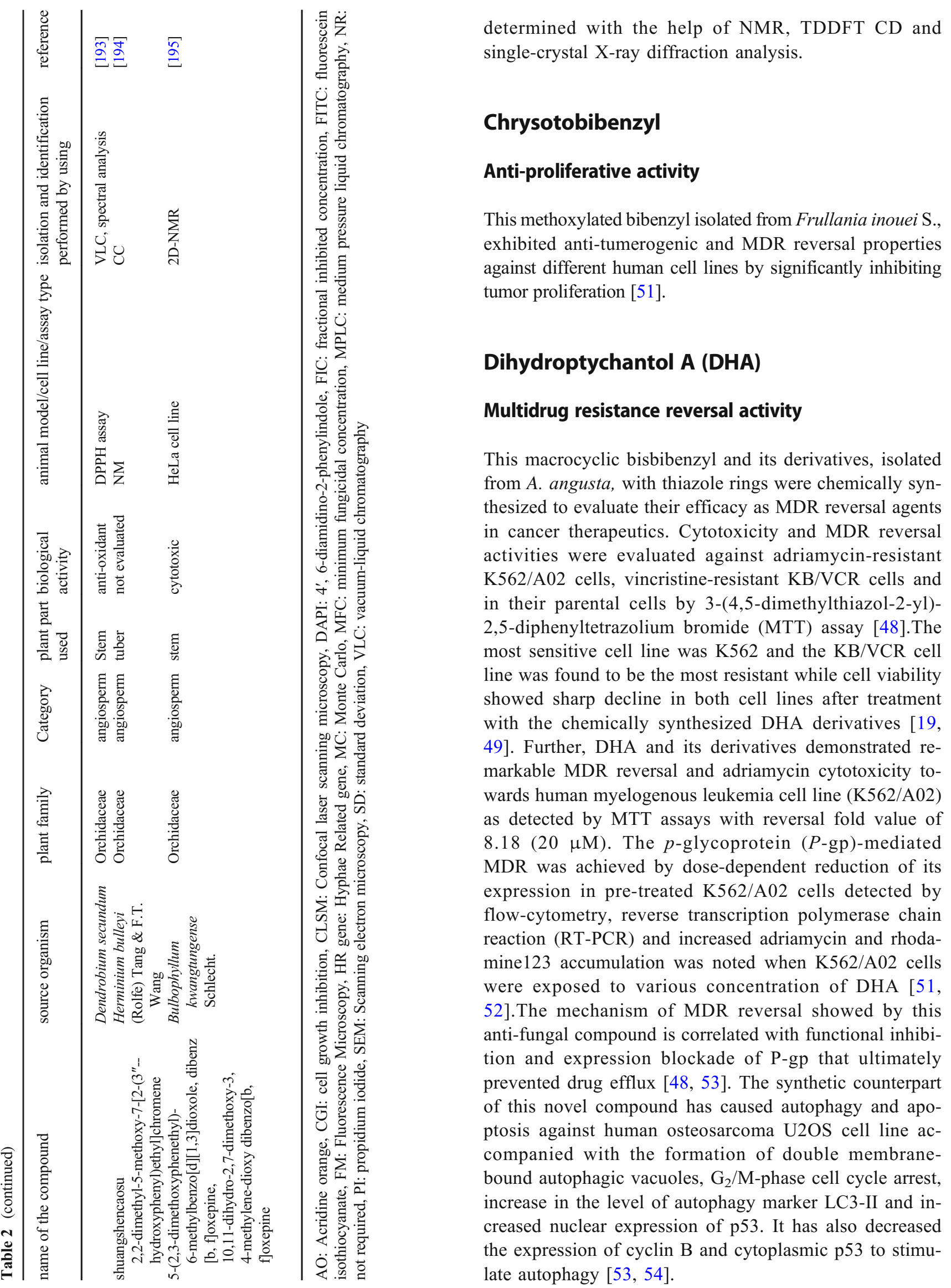

determined with the help of NMR, TDDFT CD and single-crystal X-ray diffraction analysis. exhibited anti-tumerogenic and MDR reversal properties against different human cell lines by significantly inhibiting tumor proliferation [51].

\section{Dihydroptychantol A (DHA)}

\section{Multidrug resistance reversal activity}

This macrocyclic bisbibenzyl and its derivatives, isolated from $A$. angusta, with thiazole rings were chemically synthesized to evaluate their efficacy as MDR reversal agents K562/A02 cells, vincristine-resistant KB/VCR cells and in their parental cells by 3-(4,5-dimethylthiazol-2-yl)2,5-diphenyltetrazolium bromide (MTT) assay [48].The most sensitive cell line was $\mathrm{K} 562$ and the KB/VCR cell viability ated re2/A02) value of $8.18(20 \mu \mathrm{M})$. The $p$-glycoprotein $(P$-gp)-mediated flow-cytometry, reverse transcription polymerase chain eaction (RT-PCR) and increased adriamycin and rhodamine123 accumulation was noted when K562/A02 cells ere exposed to various concentration of DHA [51, 52].The mechanism of MDR reversal showed by this nti-fungal compound is correlated with functional inhibition and expression blockade of P-gp that ultimately prevented drug efflux $[48,53]$. The synthetic counterpart of this novel compound has caused autophagy and apoptosis against human osteosarcoma U2OS cell line accompanied with the formation of double membranebound autophagic vacuoles, $\mathrm{G}_{2} / \mathrm{M}$-phase cell cycle arrest, increase in the level of autophagy marker LC3-II and increased nuclear expression of $\mathrm{p} 53$. It has also decreased late autophagy [53, 54]. 
1

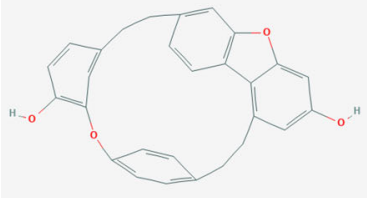

5

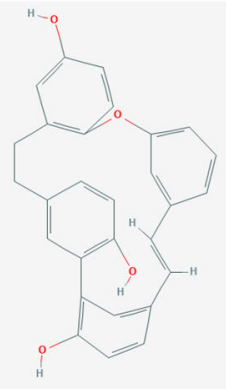

9

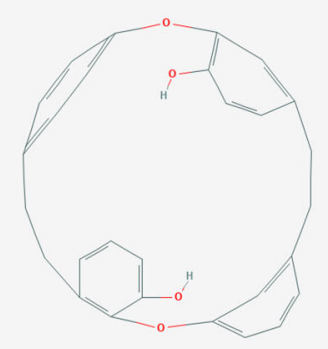

13

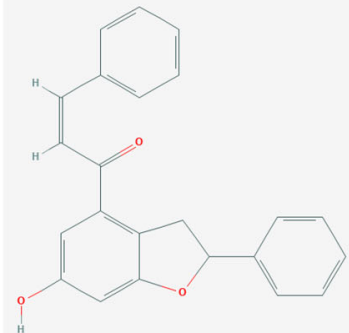

2

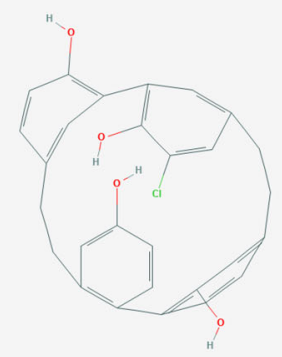

6

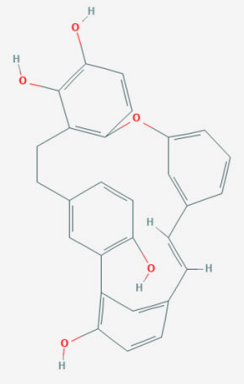

10

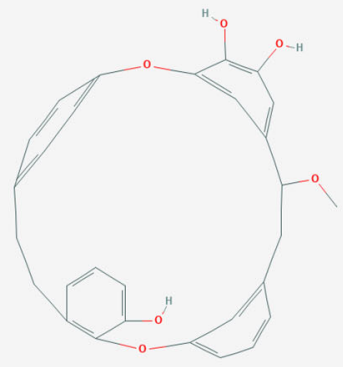

14

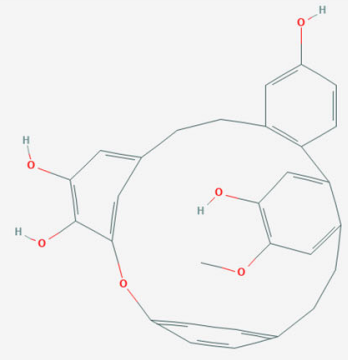

Fig. 2 Structures of bioactive bibenzyls: 1.Asterelin A (C28H22O4) 2.Bazzanin S (C28H23C1O4) 3.Brittonin A (C20H26O6) 4.Chrysotobibenzyl (C19H24O5) 5.Isoplagiochin A (C28H22O4) 6.Isoplagiochin B (C28H22O5) 7.Lunularin (C14H14O2) 8.Marchantin A (C28H24O5) 9.Marchantin C (C28H24O4) 10.Marchantin E

\section{Isoplagiochin A, Isoplagiochin B}

\section{Anti-tubulin polymerization activity}

Isoplagiochin A and $\mathrm{B}$, the macrocyclic bis(bi)benzyls were isolated from the liverwort Plagiochila fruticosa J.

3

4

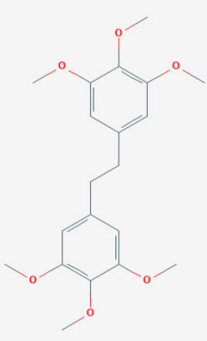

7

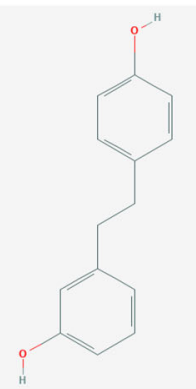

11

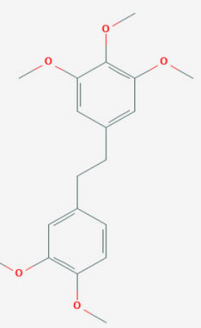

8

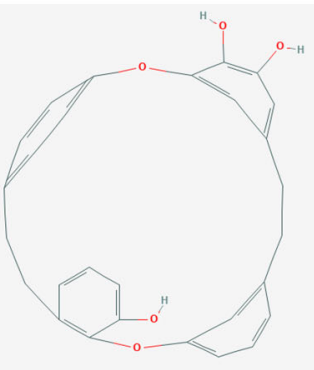

12
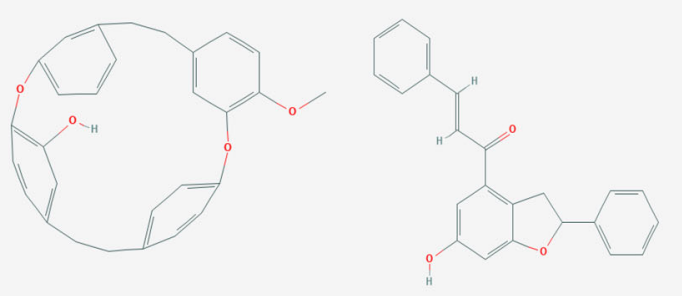

16

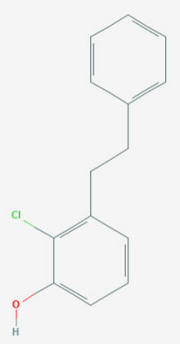

(C29H26O6) 11.Pakyonol (C29H26O4) 12.Pallidisetin A 13.Pallidisetin B (C23H18O3) 14.Plagiochin A (C29H26O6) 15.Riccardin C (C28H24O4) 16.2-chloro-3-hydroxybibenzyl (C14H13ClO)

Proc. Linn. Soc. Their structures were established using two dimentional (2D)-NMR spectra, X-ray crystallography and chemical degradation assay [55]. It is also reported from $P$. diversifolia Lindenb \& Gottsche and $P$. permista var intergerrima Herzog [47]. It has shown remarkable inhibitory effect on tubulin polymerization 
with respective $\mathrm{IC}_{50}$ value of 50 and $25 \mu \mathrm{g} / \mathrm{ml}$ [42]. Isoplagiochins $\mathrm{C}$ and $\mathrm{F}$ were also isolated from Plagiochila sp. [44].

\section{Isoplagiochin D}

\section{Anti-fungal activity}

Isoplagiochin $\mathrm{D}$ was isolated from dichloromethane and methanolic extracts of the liverwort $B$. trilobata by bioautography [49] on TLC and showed significant antifungal activity against five human pathogenic fungi in the 96-well microtiter plate assay. Solvent $(50 \mu \mathrm{l})$ was kept in negative control well and for positive control $50 \mu \mathrm{l}$ solutions of the standard drugs viz. folicur, rovral and amistar were used. It has shown highest $\mathrm{IC}_{50}$ value of $15.9 \mu \mathrm{g} / \mathrm{ml}$, against $S$. tritici, among all of the five fungi [19]. It is also reported from Lepidozia incurvata Lindenb and Herbertus sakuraii (Warnst) S. Hatt [47].

\section{Isoriccardin C}

\section{Anti-fungal activity}

This novel bisbibenzyl was isolated from Ptagiochasma intermedlum $\mathrm{L}$. and spectral data analysis was used to reveal its structural configuration. It has shown significant antifungal activity against the fluconazole-sensitive and resistant strains of C. albicans [56]. It is also reported from Lepidozia incurvata, Herbertus sakuraii, and P. fruticosa [47].

\section{Lunularin}

\section{Cytotoxic activity}

Lunularin has been isolated from Dumortiera hirsuta (Sw.) Nees. This bibenzyl compound showed moderate cytotoxic activity against human $\mathrm{HepG} 2$ cell line $\left(\mathrm{IC}_{50}\right.$ value $=7.4$ $\mu \mathrm{g} / \mathrm{ml}$ ) besides exhibiting significant anti-microbial activity against Pseudomonas aeruginosa with MIC value of 64 $\mu \mathrm{g} / \mathrm{ml}[11]$.

\section{4-hydroxylunularin}

\section{Anti-protozoal activity}

This hydroxyl-bibenzyl, has been isolated from Ricciocarpos natans Corda, August Karl Joseph. In silico, in vitro and in vivo anti-protozoal activities of this natural phytochemical were assayed against culture and intracellular forms of Leishmania sp. and Trypanosoma. Cruzi using resveratrol, pentamidine and benznidazole as standard compounds. The respective $\mathrm{IC}_{50}$ values against test organisms were $0.5,1.1,1.1$ and $17.3 \mu \mathrm{M}$. In Leishmania infected mice, oral and subcutaneous administration of the compound at a dose of $10 \mathrm{mg} / \mathrm{kg}$ of body weight for 15 days significantly decrease the lesion weight and the parasite load which clearly demonstrated its leishmanicidal potential [26].

\section{Marchantin A}

\section{5-lipoxygenase inhibitory activity}

Chromatographic quantification of the methanol extract of Japanese Marchantia polymorpha L. over silica gel and Sephadex LH-20 has successfully detected the presence of cyclic bis-bibenzyls, marchantin A (30 g) and its analogues marchantins B, C, D, E, G and J [8]. Highly pure marchantin A $(80-120 \mathrm{~g})$ has also been extracted from $6.67 \mathrm{~kg}$ of dried M. paleacea var. dipteral. It has shown 89\% 5-lipoxygenase inhibitory activity against $\mathrm{LTB}_{3}$ or $5 S, 12 R$-dihydroxy6,8,10,14-eicosatetraenoic acid at $10^{-5} \mathrm{M}$ and at the same concentration, for 5-HETE or 5-hydroxy-6,8,11,14eicosatetraenoic acid inhibition was found to be almost $99 \%$ [57].

\section{Anti-proliferative, Cytotoxic and anti-oxidant activity}

Compounds isolated from M. polymorpha and M. tosana Steph.have shown cytotoxicity against the KB cell line $[58,59]$. Bioactivity-guided separation of the compound from the extract of M. emarginata subsp. Tosana (Steph.) Bischl., was evaluated for its anticancer activity. The structural identification was performed by spectral analysis. The anti-proliferative activity of this compound has been reported against human MCF-7 breast cancer cells with an $\mathrm{IC}_{50}$ value of $4 \mu \mathrm{g} / \mathrm{ml}$ along with anti-radical activity with half-maximal response $\left(\mathrm{EC}_{50}\right) 20 \mu \mathrm{g} / \mathrm{ml}$. The alteration in expression of different cell cycle regulators such as p21, p27, cyclin B1, and cyclin D1 along with increased level of apoptotic markers viz. cleaved caspase8, caspase- 3 , caspase-9, and poly (ADP ribose) polymerase (PARP) showed the underlying mechanism of cytotoxicity. Presence of phenolic hydroxy groups at $\mathrm{C}-1^{\prime}$ and C-6' positions were assumed to be responsible for inducing cytotoxic and antioxidant activities [32]. Marchantin A exhibited anti-proliferative activity against rat myeloblast cell line $\left(\mathrm{CC}_{50} \mathrm{~L} 6\right)$ with $\mathrm{IC}_{50} 6.64 \mu \mathrm{M}$, when compared with control drug podophyllotoxin. Further, it decreased cell viability of breast cancer cell line, A256 $\left(\mathrm{IC}_{50}\right.$ 
$5.5 \mu \mathrm{M})$ and showed positively regulated synergism in the presence of the Aurora-A kinase inhibitor (MLN8237) [60]. It has been further reported against MCF7, KB and $\mathrm{A} 256$ the respective $\mathrm{IC}_{50}$ values were 11.5, 3.7 and 5.5 $\mu \mathrm{M}$; and for its analogues Marchantin $\mathrm{B}$ and $\mathrm{E}, \mathrm{IC}_{50}$ values were found to be 3.2 and $7.6 \mu \mathrm{M}$ respectively [1].

\section{Anti-trypanosomal activity}

Marchantin A has shown remarkable in-vitro antitrypanosomal activity $\left(\mathrm{IC}_{50} 0.27 \mu \mathrm{g} / \mathrm{ml}\right)$ against Trypanosoma bruceibrucei strain GUTat 3.1 and potent cytotoxicity against human $\mathrm{KB}$ cell line [61] and human MRC-5 cells $\left(\mathrm{IC}_{50} 3.60 \mu \mathrm{g} / \mathrm{ml}\right)$ with moderate selectivity when compared with therapeutic standard drugs eflornithine and suramin [62].

\section{Anti-microbial activity}

Significant anti-microbial activity for marchantin A was reported [57], against different bacteria such as Acinetobacter calcoaceticus (MIC $6.25 \mu \mathrm{g} / \mathrm{ml}$ ), Bacillus cereus (MIC $12.5 \mu \mathrm{g} / \mathrm{ml}$ ), Cryptococcus neoformans (MIC $12.5 \mu \mathrm{g} / \mathrm{ml}$ ), B. megaterium (MIC $25 \mu \mathrm{g} / \mathrm{ml}$ ), Salmonella typhimurium (MIC $100 \mu \mathrm{g} / \mathrm{ml}$ ) as well as against fungi like Aspergillus fumigates, A. niger, Penicillium chrysogenum, Sporothrix schenckii, Trichophyton rubrum (MIC $100 \mu \mathrm{g} / \mathrm{ml}$ for all fungal species) $[8,58,59]$.

\section{Anti-protozoal activity}

Marchantin A, extracted from diethyl ether extract of M. polymorpha has shown in-vitro anti- protozoal activity against Plasmodium falciparum, Leishmaniadonovani, Trypanosoma bruceirhodesiense and T. cruzi. To ensure role of marchantin A against prophylaxis of malaria, enzyme inhibition assay for PfFAS-II pathway was performed further and moderate activity of marchantin $\mathrm{A}\left(\mathrm{IC}_{50} 18.18 \mu \mathrm{M}\right)$ was noted [60].

\section{Other pharmacological activities}

Marchantin A has been reported for its wide range of therapeutic application apart from the above-mentioned ones; which include significant calmodulin inhibitory activity $\left(\right.$ ID $\left._{50} 1.85 \mu \mathrm{g} / \mathrm{ml}\right)$ [57], cyclooxygenase inhibitory activity $\left(\mathrm{IC}_{50} 46.4 \mu \mathrm{M}\right)$ [59], DNA polymerase $\beta$ inhibition, in-vivo muscle relaxing capacity and cardiotonic activity $(0.1 \mathrm{mg}$ compound increased coronary blood flow at rate of $2.5 \mathrm{ml} / \mathrm{min}$ ) [63-65]. The presence of marchantin A was also reported in oil bodies of M. polymorpha [66].

\section{Marchantin A trimethyl ether}

\section{Muscle relaxation activity}

This compound is a derivative of marchantin A, possessing similar macrocyclic skeleton structure. Pharmacological study has revealed its significant skeletal muscle relaxation activity which was found to be about 3.5 times greater than that of standard drug d-tubocurarine. Moreover, it caused dose dependent reduction of contraction in frog rectus abdominus [64].

\section{Marchantin C}

\section{Cytotoxic activity}

Marchantin C was isolated by bioactivity-directed isolation from Schistochila glaucescens (Hook) A. It was extracted and screened for cytotoxicity against P388 leukaemia cells [67]. It has also been identified from D.hisuta extract via spectral analysis [11]. Further the dose-dependent pro-apoptotic effect of this macrocyclic bis(bi)benzyl has been observed in human glioma A 172 cells through RT-PCR and western blot assay. Morphological studies and DNA laddering assay confirmed the inhibitory effects of marchantin $\mathrm{C}$ on cellular growth, viability and colony forming capacity of treated A 172 cells accompanied with nuclear fragmentation, appearance of apoptotic bodies and DNA laddering fragments which could be the outcome of regulation of Bax-Bcl-2 proteins resulted in in vivo and in vitro anti-tumor activity mediated by cell cycle arrest in A172 and reduction in microtubule quantity in Hela cells [29, 43]. Human cervical carcinoma xenografts exhibited increased expression level of apoptosis with inducers like cyclin B1, Bax and caspase-3 [43, 68]. Matrix metallopeptidase 2, the main factor associated with migration of cancer cells was found to be reduced in marchantin $\mathrm{C}(8-16 \mu \mathrm{M})$ treated T98G and U87 glioma cells [69]. Marchantin $\mathrm{C}$ and its synthetic dimethyl ether derivative, 7,8-dehydromarchantin $\mathrm{C}$ was found to alter reversal of vincristine-resistance in $\mathrm{KB} / \mathrm{VCR}$ cells [70]. By using conditional media for endothelial cell tube formation assay, role of marchantin $\mathrm{C}$ has been observed on angiogenic inhibition of $\mathrm{T} 98 \mathrm{G}$ glioma cells by up-regulating sFlt-1 [71]. Significant microtubule depolarizing capacity was also observed in KB, MCF7 and PC3 cell lines [16]. First report on the $\alpha$-glucosidase inhibitory activity of macrocyclic bisbibenzyls was obtained from this compound $(52.2 \%$ at $1 \mathrm{mM}$ ) [28]. 


\section{Marchantin C isomer (Isomarchantin C)}

\section{Enzyme inhibitory activity}

Isomarchantin C, isolated from M. polymorpha and M. palmata Reinw.Nees \& Blume showed strongest inhibitory effect against cathepsins L (95\%) and cathepsin B (93\%), (both were related to osteoporosis and allergy) at $10^{-5} \mathrm{M}$ concentration. These enzymes are elated with osteoporosis and allergy $[59,71]$.

\section{Marchantin E}

\section{Enzyme inhibitory activity}

This antifungal bibenzyl, extracted from the liverwort Frullania muscicola Steph is an important enzyme activity modulating agent [73]. The spectral diffraction analysis by infra-red (IR), ultra-violet (UV), 1-dimentional (1D)-NMR, 2D-NMR, and optical rotatory dispersion (ORD) spectroscopy have confirmed the structure of the compound [56, 74], and the compound was found to prevent calmodulin activity $\left(\mathrm{ID}_{50}\right.$ $2 \mu \mathrm{g} / \mathrm{ml}$ ) [58]. Significant cyclo-oxygenase $\left(\mathrm{IC}_{50} 58.0 \mu \mathrm{M}\right)$ and 5-lipoxygenaseinhibitory activity was also reported [64, 75]. respectively. Presence of 3,4-dihydroxyphenethyl group in structural moiety played an important role on inhibition of PA endonuclease in-vitro which may be termed as "fitting and chelating model". The compound was also found to capable of inhibiting the growth of $\mathrm{H} 3 \mathrm{~N} 2$ as well as H1N1 influenza A and $\mathrm{B}$ viruses [76].

\section{Marchantin H}

\section{Anti-oxidant activity}

This macrocyclic bis(bi)benzyl can function as an effective chaperone protecting antioxidant [3] against peroxidative damage. It was reported to inhibit nonenzymatic iron-induced lipid peroxidation in rat brain homogenates $\left(\mathrm{IC}_{50}=0.51 \pm 0.03 \mu \mathrm{M}\right)$ and suppressed $\mathrm{NADPH}$-dependent microsomal lipid peroxidation $\left(\mathrm{IC}_{50}=\right.$ $0.32 \pm 0.01 \mu \mathrm{M})$ when compared with the standard drug desferrioxamine. Due to its anti-radical activity concentration-dependent reduction in oxygen consumption during peroxyl radical-induced human erythrocyte ghost oxidation has been observed [56]. This versatile biomolecule also inhibit copper-induced human lowdensity lipoprotein oxidation as well as alleviated superoxide anions generated by the xanthine/xanthine oxidase system.

\section{Anti-microbial activity}

The anti-microbial efficacy of this potent antioxidant compound has been examined in-vitro against the fluconazole drug resistant strains of the pathogenic fungi C.albicans. It was found that for both tested strains (CA 02 and CA 10) the MIC value of marchantin $\mathrm{H}$ was 256 $\mu \mathrm{g} / \mathrm{ml}[55]$.

\section{Marchantin M}

\section{Cytotoxic activity}

Marchantin M, a cyclic bisbibenzyl, isolated from A.angusta extract was found to be cytotoxic against chemo-resistant prostate cancer PC3 cells. Inhibition of cell proliferation was detected by MTT assay as well as time and dose dependent elicitation of apoptosis $\left(\mathrm{IC}_{50}\right.$ value $\left.=5.45 \mu \mathrm{M} / \mathrm{l}\right)$ along with upregulation of Bax expression. PARP cleavage and caspase-3 activity were confirmed by western blotting, flow cytometry and morphological observations [77]

\section{1-0-demethyl Marchantin I}

\section{Anti-microbial activity}

This dibenzofuran bisbibenzyl was extracted from A. angusta and spectral analysis through X-ray crystallography has confirmed the structural moiety. The application of microdilution assay and TLC bioautographic assay were used to elucidated its antifungal attributes [48].

\section{NeomarchantinA,Neomarchantin B}

\section{Cytotoxic activity}

These phytochemicals were isolated by the bioactivitydirected isolation from the extracts of $S$. glaucescens along with marchantin $\mathrm{C}$ and a mixture of sesquiterpene/ bis-bibenzyl dimers which have shown significant cytotoxicity against $\mathrm{P} 388$ cell line with $\mathrm{IC}_{50}$ value of $8-18$ $\mu \mathrm{g} / \mathrm{ml}[66]$.

\section{Anti-fungal activity}

Neomarchantin A, a potent anti-fungal compound against the pathogenic strain of $C$. albicans, was isolated from the hydroalcoholic extract of air-dried thallus of M. polymorpha. Application of TLC bioautography assay has shown minimum inhibitory dose value of this compound was $0.25 \mu \mathrm{g}$ 
when compared with standard control miconazole ${ }^{1} \mathrm{H}$ - and

${ }^{13} \mathrm{C}$-NMR data were compared for the structural elucidation [20]. It was also reported for its in-vitro anti-fungal activities [55].

\section{Pakyonol}

\section{Cytotoxic and anti-proliferative activity}

Pakyonol, a macrocyclic bisbibenzyl, obtained from Plagiochasma intermedium (Horik.) Inoue has inhibited androgen-insensitive $\mathrm{PC}_{3}$ cell proliferation and decreased cell viability by $9.8 \%, 23.2 \%, 42.1 \%, 56.8 \%$ respectively at concentration of $5,10,20$, and $50 \mu \mathrm{M} / 1$ in a dosedependent and time-dependent manner [77]. It has also showed growth inhibitory activity against $C$. albicans. It was also found to be effective in alleviating P-gp mediated MDR in adriamycin-induced tumor cell line K562/A02 mediated by 4.78 -fold decrease in $\mathrm{IC}_{50}$ value in the presence of $3 \mu \mathrm{g} / \mathrm{ml}$ pakyonol under $48 \mathrm{~h}$ treatment. The regulatory drug transport activity of this natural compound has been determined by intracellular accumulation and retention of the rhodamine-123 in resistant cancer cells [55].

\section{Paleatin B}

\section{Cytotoxic and enzyme inhibitory activities}

This acyclic bis-bibenzyl isolated from the thalloid liverwort M. paleacea var. diptera(Nees\& Mont.) S. Hatt. showed cytotoxicity against $\mathrm{KB}$ and $\mathrm{P}-388$ cell line. It also demonstrated DNA polymerase $\beta$ and cyclooxygenase inhibitory activities with $\mathrm{IC}_{50}$ value of $45.2 \mu \mathrm{M}$ [64].

\section{Pallidisetin A, Pallidisetin B}

\section{Cytotoxic activity}

These cinnamoyl bibenzyls were isolated via bioassayguided fractionation of an ethanolic extract of Polytrichastrum pallidisetum (family: Polytichaceae) and spectral analyses and chemical correlation were employed to elucidate their structures. It showed cytotoxic efficacy against different human tumor cell lines, viz. RPMI-7951 melanoma and U-251 Glioblastoma multiforme has been reported many years back [15].

\section{Perrottetin A-D}

\section{Anti-microbial and enzyme inhibitory activity}

Prenyl bibenzyls, perrottetin A-D isolated from the liverwort $R$. perrottetii showed anti-microbial activity against Streptococcus aureus. Their structures have been determined by spectral methods and chemical transformation analyses [7]. Perrottetins were reported to have 5-lipoxygenase and cyclooxygenase inhibitory activities $[56,64,78]$.

\section{Perrottetin E}

\section{Cytotoxic activity}

This prenyl bibenzyl, extracted from $R$. perrottetii, exhibited pronounced cytotoxicity ( $\mathrm{ID}_{50} 12.5 \mu \mathrm{g} / \mathrm{ml}$ ) against the human KB cells [58]. Ether analogues of this bis(bi)benzyl, (perrottetin $\mathrm{F}$ and perrottetin $\mathrm{G}$ ), were also isolated from same source $[79,80]$.

\section{Anti-thrombin activity}

Perrottetin E isolated from Jungermannia comata Nees was tested for anti-thrombin activity $\left(\mathrm{IC}_{50} 18 \mu \mathrm{M}\right)$ which was correlated with blood coagulation and cardioprotection [81].

\section{Perrottetin F}

\section{PA endonuclease inhibitory activity}

Perrottetin F isolated from Plagiochila sciophila, Nees ex Lindenb, showed significant DNA polymerase $\beta$ inhibitory activity as well as in vitro PA endonuclease inhibitory activity due to the presence of 3,4-dihydroxyphenethyl group in its structural moiety, indicating its potential as new therapeutic agent in influenza A inhibition [1].

\section{Anti-viral activity}

This compound was also reported to decrease the viral infectivity titer and the inhibition of growth the influenza $\mathrm{B} /$ Malaysia/2506/2004 virus at a dose of $50 \mu \mathrm{M}$ [76].

\section{Plagiochin A}

\section{PA endonuclease inhibitory activity}

Plagiochin A, a medicinally potent marchantin-related phytochemical, extracted from M. polymorpha was found to inhibit 
influenza PA endonuclease activity in vitro and also exhibited significant activity against virus infectivity titer [76].

\section{Anti-trypanosomal activity}

This compound hasc also been isolated from P. sciophila and exhibited significant in-vitro anti-trypanosomal activity against $T$. brucei with $\mathrm{IC}_{50}$ values ranging from $0.69-0.93$ $\mu \mathrm{g} / \mathrm{ml}$. Its moderate cytotoxicity against human MRC- 5 cell was determined by selectivity index [cytotoxicity $\left(\mathrm{IC}_{50}\right.$ for the MRC-5 cells)/anti-trypanosomal activity ( $\mathrm{IC}_{50}$ for the GUT at 3.1strain)] [61].

\section{Neurotrophic Activity}

The compound was reported for up-regulation of choline acetyl transferase activity at $10^{-6} \mathrm{M}$ in a neuronal rat brain cell culture [82].

\section{Plagiochin E}

\section{MDR reversal activity}

This bisbibenzyl compound, isolated from Marchantia polymorpha, exhibited profound MDR reversal activity [28]. However, pro-apoptotic metacaspase dependent pathway was also found to be induced by plagiochin $\mathrm{E}$ in $C$. albicans [83]. Plagiochin E down-regulated the expressions of CLB2, CDC28 and CLB4 that ultimately caused G2/M cell cycle arrest. Moreover, enhanced cytochrome c release, nuclear fragmentation and metacaspase activation by the compound also promoted yeast apoptosis [83]. Microscopic study revealed antifungal mechanism of this macrocylic bisbibenzyl is closely associated with cell wall degradation, enzymatic inhibition of chitin synthatase, in-vitro and in-vivo, as well as up-regulation of gene $C H S 2$ and $C H S 3$, and downregulation of $C H S 1$ [2]. The anti-fungal efficacy of plagiochin E against $C$. albicans could be derived from enhancement of mitochondrial F0F1-ATPase, as well as mitochondrial membrane potential, the activity of mitochondrial dehydrogenases was blocked that resulted into depletion of ATP production and ultimately ROS accumulation [83].

\section{Pusilatins A-D}

\section{DNA polymerase inhibitory activity}

These bisbibenzyl dimers, extracted from B. pusilla, were reported for different bioactivities $[58,85]$. Pusilatin $\mathrm{B}$ and $\mathrm{C}$ have shown weak HIV-ameliorative activity, moderately inhibited the activity of DNA polymerase $\beta\left(\mathrm{IC}_{50} 13\right.$ and
$5.16 \mu \mathrm{M}$ respectively); Pusilatin $\mathrm{B}$ and $\mathrm{C}$ have also exhibited cytotoxicity in $\mathrm{KB}$ cells $\left(\mathrm{ED}_{50} 13.1\right.$ and $13 \mu \mathrm{g} / \mathrm{ml}$ respectively) [85].

\section{Radulanin A, Radulanin L, Radulanin K}

\section{Anti-oxidant activity}

Greenish oil ether extract of Radula appressa Mitt., houses these prenyl bibenzyls that showed moderate anti-oxidant efficacy by inhibiting nitric oxide production in lipopolysaccharide stimulated RAW 264.7 cell line with respective $\mathrm{IC}_{50}$ value of $20 \mu \mathrm{M}$ and $15.3 \mu \mathrm{M}$ [28]. Radulanin L, a novel dihydrooxepin obtained from $R$. complanata was structurally elucidated by comparing ${ }^{1} \mathrm{H}$ and ${ }^{13} \mathrm{C}$ NMR spectral data with previously discovered radulanin A and radulanin $\mathrm{H}[7,13]$. Radulanin $\mathrm{K}$ from $R$. javanica inhibited the superoxide anion radical release from guinea pig macrophage with $\mathrm{IC}_{50}$ value 6 $\mu \mathrm{g} / \mathrm{ml}$ and also possessed significant cyclooxygenase inhibitory activity $\left(\mathrm{IC}_{50} 39.7 \mu \mathrm{M}\right)$ [64].

\section{Radulanolide}

\section{Anti-microbial activity}

This novel prenyl bibenzyl, produced by $R$. complanata was screened for antimicrobial activity against $S$. aureus $[13,80]$.

\section{Riccardin A, Riccardin B}

\section{5-lipoxygenase inhibitory activity}

These cytotoxic cyclic bisbibenzyls were obtained from Riccardia multifida (L.) S. Gray and their structure determination was done by X-ray diffraction analysis and $400-\mathrm{MHz}$ $\mathrm{H}^{1} \mathrm{NMR}$ analysis. These were the first bis-bibenzyls to inhibit $\mathrm{KB}$ cells at a concentration of 10 and $12 \mu \mathrm{g} / \mathrm{ml}$, respectively besides demonstrating potent 5 -lipoxygenase inhibitory activity $[8,35,58]$.

\section{Riccardin C}

\section{Cytotoxic activity}

This cyclic bisbibenzyl with cyclooxygenase inhibitory activity was obtained from the Chinese liverwort $P$. intermedlum. It was also reported from Reboulia hemisphaerica (L.) Raddi [7]. Riccardin C is a dimethoxy derivative of riccardin A [7]. It enhanced cholesterol efflux from THP-1cells and can 
increased plasma HDL level without elevating triglyceride level in mice [44, 86, 87], as it worked as the liver Xreceptor (LXR) $\alpha$ agonist and (LXR) $\beta$ antagonist [58]. AIt was found to be cytotoxic to human prostate cancer PC 3 cells via inducing apoptosis with an $\mathrm{IC}_{50}$ values of $3.22 \mu \mathrm{M} / 1$ and was also able to modulate the expression levels of apoptosisrelated proteins (Bcl-2, Bax and PARP). For $10 \mu \mathrm{M} / 1$ riccardin $\mathrm{C}$, total percentage of apoptotic cells were found to be 6.21 accompanied with $0.1 \%, 3.4 \%, 84.1 \%, 88.3 \%$ repression of cell viability at different concentrations of this bisbibenzyl under 24,48 , and $72 \mathrm{~h}$ treatment [77].

\section{Anti-fungal activity}

A. angusta (family: Aytoniaceae) is another source of riccardin C. It has shown potent in vitro anti-fungal properties along with synergistic fungal resistance modifying capacity when applied on three resistant strains of $C$. albicans in combination with fluconazole [55, 64].

\section{Riccardin D}

\section{Anti-proliferative and chemo-preventive activities}

The macrocyclic bis(bi)benzyl, detected in the liverwort, Monoclea forsteri Hook [12] has demonstrated antiproliferative activity on human glioma A172 cells and induced apoptosis at a dose of $16 \mu \mathrm{M}$ and caused reversal of P-gp-mediated MDR [88]. It was also isolated from the liverwort $D$. hirsuta and significantly affected the biofilm formation in C. albicans through downregulating the mRNA expression levels of hyphae specific genes and inhibited hyphal growth which were determined by the XTT (2,3-bis(2methoxy-4-nitro- 5-sulfo-phenyl)-2H-tetrazolium-5carboxanilide) reduction assay and live/dead cell staining [31]. This compound altered the activity of DNA topoisomerase II and thus functioned as natural therapeutic agent against cancer. Weekly incubation of human umbilical vascular endothelial cells (HUVEC) with riccardin D has effectively reduced cell proliferation marked by MTT assay. It has also decreased the motility and migration of treated cells, blocked capillary tube formation and reduced the level of some angiogenic factors such as VEGF (vascular endothelial growth factor), phospho-VEGF receptor 2, EGF receptor and MMP-2 (matrix metalloproteinase). Such angiogenic reduction was also observed in H460 (human lung cancer carcinoma) cell line via CD34 immuno-histochemical staining and xenograft analysis [89]. It has exhibited remarkable DNA topoisomerase-II dependent anti-proliferative effect on human leukemia cell lines viz. HL-60, K562 and MDR K562/A02 cells dependent $[67,90]$. The brominated and aminomethylated derivatives of riccardin $\mathrm{D}$ have shown significant anti-proliferative activity against KB, MCF-7 and PC3 cell lines and caused microtubule depolymerization. Such activity of this macrocyclic bisbibenzyl indicates applicability of the compound as potent chemotherapeutic agent [91]. The treatment of $A P C^{\mathrm{Min} / \mathrm{+}}$ mice with riccardin $\mathrm{D}$ for 7 weeks has significantly inhibited intestinal adenoma formation, and reduced polyp number by $41.7 \%, 31.1 \%, 44.4 \%$ and $79.3 \%$ respectively, in proximal, middle and distal portions of small intestine and colon as detected via immune-histochemical staining. To elucidate chemopreventive mechanism of riccardin D, western blotting, RT-PCR and enzyme-linked immunosorbent assay in intestinal polyps were performed and anti-proliferative and anti-angiogenic activity of this compound have been revealed. It has also downregulated the $W n t$ signaling pathway and altered the levels of inflammatory mediators present in polyps [92].

\section{Biofilm inhibitory activity}

Underlying mechanism behind therapeutic application of riccardin-D against $C$. albicans biofilms formation was evaluated through XTT reduction assay, quantitative real-time RT-PCR, scanning electron microscopy and laser confocal scanning. Riccardin-D had altered the Ras-cAMP-Efg pathway by downregulation of hypha-specific genes such as $A L S 1, A L S 3, E C E 1, E F G 1, H W P 1$ and $C D C 35$ which resulted in retardation of hyphal growth, defective biofilm maturation and dose-dependent antifungal activity when used alone or with fluconazole [91].

\section{Riccardin F}

\section{Reversal of adriamycin induced drug resistance}

Riccardin F, a macrocyclic bisbibenzyl isolated from $P$. intermedium exhibited anti-fungal activity against fluconazole resistant and sensitive strains of $C$. albicans accompanied with alteration of $\mathrm{P}$-gp mediated drug resistance in adriamycin treated cancer cell line K562/A02 following a $48 \mathrm{~h}$ treatment. By monitoring fluorescence intensity of rhodamine-123, drug transportation capability of P-gp was determined. Retention of this fluorescence substrate for P-gp has indicated that MDR reversal and recovery of adriamycin accumulation by riccardin $\mathrm{F}$ is correlated with inhibition of P-gp activity [55, 93].

\section{2-geranyl-3,5-dihydroxybi-benzyl}

\section{Anti-oxidant and enzyme inhibitory activity}

The compound was extracted from $R$. Kojana and has shown significant lipoxygenase and calmodulin inhibitory 
activities [80]. Further, this compound extracted from $R$. appressa showed strong nitric oxide inhibitory activity in-vitro in cultured cell line of lipopolysaccharide stimulated RAW 264 with $\mathrm{IC}_{50}$ value $4.5 \mu \mathrm{M}$, stronger than that of standard drugL- $\mathrm{N}^{6}$-1-iminoethyl)lysine (18.6 $\mathrm{uM})$. The structure determination was performed by $2 \mathrm{D}$ NMR and CD spectral analyses [28].

\section{2,4,6-trichloro-3-hydroxybi- benzyl, 2,4-dichloro-3-hydroxybibenzyl, 2-chloro-3-hydroxybibenzyl}

\section{Anti-microbial activity}

These chlorinated bibenzyl, isolated from the liverwort $R$. marginata (family: Aneuraceae) showed significant antimicrobial activity against gram positive bacteria Bacillus subtilis, pathogenic fungus $C$. albicans, dermatophytic fungus Trichophyton mentagrophytes and the plant pathogenic fungus Cladosporium resinae, at $30 \mu \mathrm{g}$ per disk concentration. 2,4-dichloro-3-hydroxybibenzyl was proved to be the most potent against $T$. mentagrophytes and $C$. resinae with zone of inhibition of 12 and $2 \mathrm{~mm}$ respectively [94].

\section{2,6-dichloro-3-hydroxy-4'-methoxybibenzyl, 2,6,3'-trichloro-3-hydroxy-4' -methoxybibenzyl,2,4,6,3'-tetrachloro-3 -hydroxybibenzyl 2,4,6,3'-tetrachloro -3,4-dimethoxybibenzyl}

\section{Anti-fungal and anti-feedant activities}

These bioactive polychlorinated bibenzyls were the arsenal of some Riccardia sp. against pathogens and herbivores. TLC-bioautographic study with a Cladosprium herbarum culture, showed fungicidal activities greater than standard ketoconazole with inhibition zones ranging from $1.2 \mathrm{~cm}$ to $2.9 \mathrm{~cm}$, manifested by these compounds except 2,4,6,3'-tetrachloro-3-hydroxybibenzyl. 2,6,3'trichloro-3-hydroxy-4'-methoxybibenzyl and 2,4,6,3'tetrachloro-3-hydroxybibenzyl were also tested for antifeedant activity against Spodoptera littoralis larvae and showed moderate result at $\mathrm{FR}_{50}=0.63$ and 0.43 respectively. These chlorinated bibenzyls were also assayed for brine shrimp lethality activity at $50 \%$ lethal concentration ( $\left.\mathrm{LC}_{50}\right)$ 0.42-2.35 ppm, with two standard drugs ketoconazole and asuntol with $\mathrm{LC}_{50}$ value $14.9 \mathrm{ppm}$ and 10.8 ppm respectively [25].
2(R)-2-isopropenyl-6,7dihydroxy-4-(2-phenylethyl) dihydrobenzofuran

\section{Anti-trypanosomal activity}

This prenyl bibenzyl, isolated from $R$. perrottetii demonstrated significant anti-trypanosomal activity against T.brucei, with an $\mathrm{IC}_{50}$ value of $0.44 \mu \mathrm{g} / \mathrm{ml}$ [13] which are 3.6- and 5.2-fold higher than the standard drugs suramin and eflornithine, respectively. It has also demonstrated slight cytotoxicity against human diploid embryonic cell line MRC-5 with an $\mathrm{IC}_{50}$ value $7.46 \mu \mathrm{g} / \mathrm{ml}$ [61].

\section{3-hydroxy-4'-methoxybibenzyl}

\section{Anti-fungal activity}

The compound, isolated from the liverwort $F$. muscicola (family: Frullaniaceae), showed anti-fungal activity through bioassay directed analysis. Structure confirmation was accomplished via spectral data analysis of IR, UV, NMR as well as ORD [74].

\section{3-methoxy-4'-hydroxybibenzyl}

\section{Nematocidal activity}

3-methoxy-4'-hydroxybibenzyl isolated from the New Zealand liverwort, Plagiochila stephensoniana Mitt, showed in vitro nematode larval motility with an $\mathrm{IC}_{50}$ value of 0.13 $\mathrm{mg} / \mathrm{ml}$ against the third-stage larvae of the sheep parasite, Trichostrongylus colubriformis [95].

\section{3,3',4,4'-tetramethoxybibenzyl}

\section{Anti-proliferative activity}

This bibenzyl obtained from $F$. inouei was found to be highly methoxylated and cytotoxic to different human tumor cell lines. It has shown significant anti-proliferative efficacy accompanied with potent reversal of MDR [51]

\section{3, 4'-dimethoxybibenzyl}

This antimicrobial prenylbibenzyl was obtained from $R$.complanata, it is chemically very close to $R$. buccinifera L. [7]. 


\section{3,5-dihydroxy-2-(3-methyl-2-butenyl) dihydroxybibenzyls}

\section{Vasopressin antagonist activity}

The bibenzyl was isolated from $R$. complnata and its ${ }^{1} \mathrm{H}$ and ${ }^{13} \mathrm{C}$ NMR spectral data were utilized for structure determination. This prenyl bibenzyl, obtained from $R$. perrottetii showed vasopressin antagonist activity at $\mathrm{ID}_{50} 27 \mu \mathrm{g} / \mathrm{ml}$ [8]. It was also obtained from R.kojana and screened for 5lipoxygenase and calmodulin inhibitory activities [13].

\section{Anti-oxidant activity}

This compound was also extracted via bioactivity-guided fractionation from the ether extract of Plagiochila ovalifolia Mitt. and showed DPPH- (2,2-diphenyl-1-picrylhydrazyl) radical scavenging anti-oxidative activity [96].

\section{3,5-dihydroxy-4-(2, 3-epoxy-3-methylbutyl) bibenzyl}

\section{Anti-microbial activity}

This prenyl bibenzyl, isolated from R.complanata, which showed some anti-microbial activity [7].

\section{4-hydroxy-3'-methoxybibenzyl}

\section{Anti-microbial activity}

This bibenzyl was isolated from three species of New Zealand liverwort genus $P$. stephensoniana Mitt. $(10.5 \mathrm{mg} / \mathrm{g}$ dry weight); P. deltoidea Lindenb. (0.54 mg/g DW) and $P$. banksiana Gottsche.(0.05 mg/gm dry weight) [44]. The alcoholic extract of $P$. stephensoniana exhibited significant anti-bacterial activity against gram-positive bacteria Bacillus subtilis with ZOI 3-5mm plus $12-300 \mu \mathrm{g}$ extract/disk when compared with chloramphenicol ( $30 \mu \mathrm{g} / \mathrm{disk})$. The minimum fungicidal activities against the yeast $C$. albicans and dermatophyte Trichophyton mentagrophytes were found to be $125 \mu \mathrm{g} / \mathrm{ml}$ and $62.5 \mu \mathrm{g} / \mathrm{ml}$, respectively, in dilution assay comparable with anti-fungal drug nystatin [97].

\section{Cytotoxic activity}

It showed cytotoxicity against the cell line of monkey kidney cells (BSC), at $60 \mu \mathrm{g} /$ well but no significant inhibition was observed against the growth of P-388 leukemia cell line ( $\mathrm{IC}_{50}$ $>25.0 \mathrm{pg} / \mathrm{ml}$ ) when compared with to mitomycin-C [97].

\section{4,4'-dihydroxybibenzyl}

\section{Anti-fertility inhibiting activity}

The chemically synthesized isomers of 4,4'dihydroxybibenzyls has shown different anti-oestrogenic and fertility inhibiting efficacy in mice model. Among different isomeric configurations, erythro- $\alpha$-ethyl- $\alpha$-methyl 4,4 'dihydroxybibenzyls is a potent pro-oestrogen. It has shown highest anti-oestrogenic and anti-fertility activities activities intra-vaginally when applied in a dose lesser than $1 \mu \mathrm{g} / \mathrm{day}$ [98].

\section{3'-O-isoproylidenericcardin D}

\section{Anti-fungal activity}

This compound was isolated as an artefact during separation of the ethanolic extract of M.polymorpha though not detected by HPLC/MS method. It has shown effective growth inhibiting property against C.albicans detected by TLC bioautography with minimum inhibitory dose (MID) value $0.4 \mu \mathrm{g}[20]$.

\section{Bibenzyl cannabinoids: therapeutically most studied derivatives of bibenzyls}

The novel bibenzyl cannabinoid (BC), perrottetinenic acid, have been isolated from ether extract of Radula marginata Gottsche, Lindenb. \& Nees; species specific variability of (-)-cis-perrottetinene content is also reported. The structure, (established by 2D-NMR), possessed similarity with $\Delta 1$-tetrahydrocannabinol, which is also a $\mathrm{BC}$ compound extracted from $R$. perrottetii [99]. Perrottetinene was also reported from Radula laxiramea Steph [100, 101], and $R$ appressa [28]. In nature, the occurrence of $\mathrm{BC}$ is very rare but due to the wide distribution of such compounds in Radula species, they are considered as chemosystematic markers of Radulaceae [14]. $\Delta 8$-tetrahydrocannabinol and $\Delta$ 9-tetrahydrocannabinol (isolated from Cannabis sativa L.), both structurally quite similar to the $\Delta 1$-tetrahydrocannabinol (isolated from $R$. perrottetii) are already reported for psychopharmacological activities [102]. No pharmacological study on $\Delta 1$-tetrahydrocannabinol has yet been reported but $R$. perrottetii has been commercially exploited for cosmetics grade cannabinoids [103]. Perrottetinen is another $\mathrm{BC}$ reported from $R$. perrottetii and its structure has been established by spectral analysis [10]. Radula species is also enriched in different variants of prenylated bibenzyl which are ortho-derivative or abnormal cannabinoids [99]. Synthesis of bibenzyl/o-cannabicyclol hybrid along with some bibenzyl/monoterpenoid hybrids and 
prenyl bibenzyl derivatives have also been reported [104]. This represents bibenzyl iso-tetrahydro cannabinoids from Radula species [12, 75]. Total synthesis of (-)-cisperrottetinene and its in vitro pharmacological activity on experimental $\mathrm{BALB} / \mathrm{c}$ mice model have also been documented [105]. They demonstrated the ability of both cis-perrottetinene and $\Delta$ 9-trans-tetrahydrocannabinol are to trigger hypothermic response by affecting expression of cannabinoid receptors (human cannabinoid receptor type 1, CB1R). Moreover, these compounds affect activity of endocannabinoid-degrading enzymes [105]. Cannabinoid type drugs are presently recommended for many neurodegenerative disorder, antineoplastic chemotherapy, post-traumatic stress (PTS), epilepsy, multiple sclerosis etc. and therefore these compounds have immense commercial prospects in medical industry. These compounds are known to ameliorate the progression of atherosclerosis, myocardial and cerebral ischaemia [106]. Identification and validation of genes [cannabigerolic acid (CBGA), stilbene acid (SA) geranyl diphosphate (GPP)] associated with cannabinoid biosynthesis have already been achieved [103]. Moreover, transcriptome analysis based approach revealed the presence of six transcription factor (TF)family unique in $R$. marginata. Considering all these facts, it maybe concluded that Radula could function as an alternative cannabinoid resource [107] and manipulation of cannabinoid synthesis pathway via genetic engineering could widen our knowledge in this aspect [108].

\section{Therapeutic application of bibenzyls and its derivatives, extracted from non-bryophytic sources}

Dendrobium is not only an important genus of the plant family Orchidaceae but it is also extensively reported in traditional Chinese remedies against a list of ailments due to the presence of variable types of secondary metabolites [109]. Therapeutic properties of the plant is contributed by polysaccharides, coumarins, sesquiterpenes, stilbenoids, phenanthrenes, alkaloids and fluorenones. Bibenzyls and bisbibenzyls are also reported from different species of the genus for their significant therapeutic activities $[110,111]$ (Table-2). Several researchers elucidated the free radical scavenging activity of different phytochemicals and possible contribution of anti-oxidative property to boost other bioactivities; bibenzyls derived from Dendrobium are of no difference [112]. For example, enzymatic antioxidant efficacy is reported for dendrocandins C-E, gigantol and batatasin II isolated from D. candidum [113], and D. chrysanthum respectively $[114,115]$. Bibenzyl compounds obtained from ethanolic extract of $D$. denneanum showed dose-dependent free radical scavenging activity determined by ORAC (oxygen radical absorbance capacity) assay, DPPH, pyrogalbl autoxidation method and Fenton reaction
[116]. An anti-androgenic bibenzyl, bifluranolhas been reported to possess curative properties against benign prostatic hyperplasia [117]. Moreover, moscatilin derived from $D$. nobile Lindley ameliorated the ischemia/hypoxia of retinal cells [118]. Table 2 summarizes the bioactive properties of different bibenzyl and bis-bibenzyl derivatives isolated from different sources apart from the bryophytes. Moreover, in these plants, many other compounds with bibenzyl skeleton have already been reported. Analysis of structural moiety and determination of chemical class has been worked out using spectroscopic or chromatographic techniques but for all these compounds clinical and/or preclinical trials are not yet performed. In the next paragraph, we have compiledinformation on bibenzyl components isolated mostly from Orchidaceae family.

Bibenzyls such as moenylin, moscatilin and isoamoenylin from D. amoenum Wall. ex Lindl. [119], cumulatin (3,3'-dihydroxy-4,4',5,5'-tetramethoxy bibenzyl) and tristin $\left(3,4^{\prime}, 5\right.$ trihydroxy-3'-methoxy bibenzyl) from $D$. cumulatum Lindl. And Bulbophyllum triste Rchb. f. have been reported [120]. Batatasin-III was isolated from Cirrhopetalum andersonii Hook. f. whereas crepidatin, a novel bibenzyl derivative was identified and extracted from D. crepidatum Griff. [121]. Aloifol-I, batatasin-III, bulbophyllin, bulbophyllidin, 3-3', 5 trimethoxy bibenzyl and 3,3' dimethoxy-4,5 methylene dioxybibenzyl from the members of the orchid family have also been documented [158]. Phytochemical screening, spectroscopic analysis and NMR have revealed the presence of natural oxepines with bibenzyl moiety [5-(2,3dimethoxyphenethyl)-6-methylbenzo[d][1,3]dioxole, and the other dibenzo $[\mathrm{b}, \mathrm{f}]$ oxepine, 10,11-dihydro-2,7-dimethoxy3,4-methylene-dioxy dibenzo[b, f]oxepine], in alcoholic leaf and stem extract of Bulbophyllum kwangtungense Schlecht. [123]. This chemical class has played a critical role in chemotaxonomy and evolution of bryophytes as number of bibenzyls are reported from pteridophytes and algae too, supporting the progressive theory of evolution. Interestingly, the presence of structurally similar monomeric bibenzyls viz. lunularin, lunularic acid and prenyl bibenzyl both in some ferns (Notholaena dealbata, N. limitanea, Sceptridium ternatum) and Hepaticae is also reported [124]. Cyclic bisbibenzyl derivatives and 2,2-dimethylallyl- and geranyl bibenzyls from Hepaticae have also been recorded [7, 35, $125,126]$. Lunularic acid and its derivatives such as 3-4'dihydroxy stilbene were identified in Hydrangea macrophylla Thumb. Ser. root extracts along with cirrhopetalidin and cirrhopetalinin $[127,128]$. These compounds were also detected in Chlorophyta, Phaeophyta and Rhodophyta [127, 129, 130]. Canniprene, an iso-prenylated bibenzyl originated uniquely from Cannabis sativa L., was found to be able to inhibit inflammatory eicosanoids production via modulation of the 5-lipoxygenase pathway. Moreover, it was found to decrease the synthesis of prostaglandin through the cyclooxygenase/microsomal prostaglandin $\mathrm{E}_{2}$ synthase 
pathway. Other spiranoid bibenzyls harvested from C. sativa are cannabispiranol and cannabispirenone which showed no significant result in these bioassays [131].

In neuroprotection, scientists featured the bibenzyl compound, 20C, isolated from orchid Gastrodia elata Blume. It is also reported for oxidative stress-ameliorating efficacy against tunicamycin induced damage in endoplasmic reticulum and rotenone-triggered apoptosis [132, 133]. The rotenone-induced neurotoxicity and Parkinson's disease (PD) development involves reduction of nuclear factor erythroid 2-related factor (Nrf2)-mediated antioxidant enzyme activity as well as DJ-1 level. The $20 \mathrm{C}$ pre-treatment reverted rotenone-induced oxidative damage in $\mathrm{PC} 12$ and SH-SY5Y cell lines, triggered overexpression of hemeoxygenase-1 (HO1), activated phosphoinositide-3-kinase (PI3K)/Akt signaling pathway and blocked ShRNA-mediated DJ-1knockdown of. All these indicates novel therapeutic mechanism of $20 \mathrm{C}$ against tissue damage and progression of PD [134].

\section{Ethnobryology}

In the present era bubbling with widened popularity of "clinical herbalism", one can easily observe the worldwide extensive research on medicinal plants and subsequent studies that links ethnomedicinal properties with clinical as well as preclinical findings. However, similar extensive research outcome is quite absent in the field of ethnobryology and allied investigation on medicinal properties of bryophyte. The concept of "ethnobryology" emerged as a subject during late $1950 \mathrm{~s}$; till date it is an almost virgin area of research with fewer reports and documentation. The prime barriers in similar research are smaller size of bryophytes, restricted distribution, morphological identification as well as chemical characterization. Furthermore, most of the reports were only cited from China (Traditional Chinese Medicine) and North America. Bryophytes viz. Polytrichum, Sphagnum and Marchantia genus are mostly reported for traditional uses [135]. Later, different species of Conocephalum, Frullania, Marchantia, Riccardia and Riccia along with Reboulia hemispherica and Dumortiera hirsuta from selective areas of the eastern Himalayas were reported for their ethnomedicinal use [136].The same paper also mentioned the presence of different bibenzyls and bis(bi)benzyl derivatives from $D$. hirsuta, $R$. hemispherica, M. polymorpha and $F$. muscicola. Though, as per the present available data, correlating the presence of bibenzyl or bibenzyl derivative with ethnomedicinal usage is not possible. However, traditionally used bryophytes from Eastern Himalayan region is enriched with a number of bibenzyls and sesquiterpenoids which may have possibly contributed towards the biomedical efficacy of these species [136]. Ethnomedicinal uses, chemical constituents and pharmacological activity of 52 bryophytes belonging to 20 families of the liverwort and 13 families of the mosses were also reported [137]. Though this paper elaborately described all these aspects but it was not clearly mentioned how biochemical compounds, isolated from all these bryophytes, contributing in reported bioactive properties of the same. However, the authors understand through clinical and preclinical investigation by screening of bryophytes available in vast geographical region, could answer such ambiguity in future.

\section{Bibenzyls: structure activity relationship (SAR) studies}

The multifaceted roles played by very important class of secondary metabolites of bryophytic origin, bibenzyls and bisbibenzyls are quite fascinating. This section details the streamlined information retrieved from various in-silico, invitro, and in-vivo studies that elucidate the critical mechanism of action and correlation between structural configuration and bioactivity, of these phyto-constituents [28]. The conformational flexibility rendered by variable presence of $\mathrm{C}$-ring has greatly promoted various bioactivity and one of the book chapter [47] written on bryophytes clearly presented the positional aspects.

In this section, the contribution of functional groups, ligands, active molecules, chemical bonds and structural moiety on the myriads of bioactivities has been discussed. The bio- and chemical diversity of bibenzyls and their origin wise differences in functional aspects are largely contributed by structure-function interrelationship. Macrocyclic bis(bi)benzyls are studied mostly for bio-activities and presence of free phenolic hydroxyl group on the benzene rings that plays important inhibitory role against fungal agents whereas the presence of methylation in the $\mathrm{OH}$ groups decreases such efficacies $[19,20$, 48]. Further the results obtained from different antimicrobial assays indicated that the antifungal efficacy of macrocyclic bis(bi)benzyls depends on the bis(bi)benzyl type nucleus and additional benzene nucleus. The presence of an additional aromatic $O$-methyl group was found to reduce the in vitro antifungal activity. Macrocyclic bis(bi)benzyls exerted direct antifungal action by forming pores in cell membranes, leading to fungal cell lysis $[55,138]$. The structure-activity relationship studies supported by in silico non-stochastic quadratic fingerprinting determined that the leishmanicidal and anti-protozoal activities of 14-Hydroxylunularin are actually the outcome of $\mathrm{sp}^{3}$ hybridization and presence of free hydroxyl group on the aromatic rings [26]. Position of methoxy and hydroxyl group on bibenzyl aromatic ring and their position-effect as per the SAR have been critically demonstrated in some popular liverwort bibenzyls. As we have discussed earlier, the presence of methoxy group at C-1', C-6' and C-13 positions of marchantin $\mathrm{A}\left(\mathrm{IC}_{50}\right.$ value $\left.=0.27 \mu \mathrm{g} / \mathrm{ml}\right)$ gives rise to marchantin A trimethyl 
ether, which is functionally almost 12 -fold less active $\left(\mathrm{IC}_{50}\right.$ value $=3.24 \mu \mathrm{g} / \mathrm{ml}$ ). Furthermore, another derivative of marchantin $\mathrm{A}$, marchantin $\mathrm{C}$, lacking the hydroxyl group at the C-6' position was found to be responsible for its 10-fold less activity [63]. However, marchantin E showed similar activity $\left(\mathrm{IC}_{50}\right.$ value $\left.=0.69 \mu \mathrm{g} / \mathrm{ml}\right)$ as shown by marchantin A due to the presence of methoxy groups at the $\mathrm{C}-7^{\prime}$ ' position. If we consider both antimicrobial and anti-trypanosomal activities, hydroxyl groups at the C-1', C-6' and C-13 positions were found to be crucial for bioactivity of marchantin A. Moreover, another interesting fact is that the tautomer of marchantin $\mathrm{C}$, isomarchantin $\mathrm{C}$ possesses ether linkage at C13-C10' position with hydroxyl groups present at C-10 and C-11', but it has failed to demonstrate any anti-trypanosomal activity. Similar pattern of SAR has been followed in case of ptychantol A with weak bioactivity $\left(\mathrm{IC}_{50}\right.$ value $\left.=5.42 \mu \mathrm{g} / \mathrm{ml}\right)$. The C-13' position is highly important for anti-trypanosomal activity and compounds having hydroxyl group at this key position are generally weaker in terms of activity [28, 29, 43]. However, C-14 and C-10' biphenyl bond of plagiochin A, C-14 and C-12' biphenyl bonds of riccardin A, and $\mathrm{C}$ as well as the presence of no bond at either $\mathrm{B}$ or $\mathrm{D}$ rings in case of perrottetin $\mathrm{F}$ demonstrated moderate activity and indicated that presence of ether linkage or biphenyl bond at the $\mathrm{B}$ or $\mathrm{D}$ rings present in bis(bi)benzyls are not useful in enhancing the bioactivity of any marchantin group of compound. Another compound 2(R)-2-isopropenyl6,7-dihydroxy-4-(2-phenylethyl) dihydrobenzofuran with isopropenyl-furan moiety has shown strong inhibitory activity $\left(\mathrm{IC}_{50}\right.$ value $\left.=0.44 \mu \mathrm{g} / \mathrm{ml}\right)$ against species of Trypanosoma but 2-geranyl-3,5-dihydroxy bibenzyl showed weak anti-trypanosomal activity when compared to radulanin $\mathrm{A}$, radulanin $\mathrm{H}$ and this isopropenyl-furan bibenzyl. Later it was demonstrated that the particular difference in bioactivity was due to the presence of carboxyl group at the C-7 position of 2-geranyl-3,5-dihydroxy bibenzyl while the three others were lacking it. So both C-13' and C-7 position were found to be important for anti-trypanosomal activity. Marchantin A, marchantin E, plagiochin A and 2(R)-2isopropenyl 6,7-dihydroxy-4-(2-phenylethyl) dihydrobenzofuran all have shown potent inhibition against Trypanosoma when compared to the standard drugs eflornithine and suramin $\left(\mathrm{IC}_{50}\right.$ value 2.27 and $1.58 \mu \mathrm{g} / \mathrm{ml}$ respectively) [61].

Antioxidation or free radical scavenging activity is considered as the basic underlying mechanism of many therapeutics. Asakawa (1994) reported the superoxide anion radical scavenging role of radulanin K extracted from Radula javanica on guinea pig macrophage [57]. If we consider the chemical structure of most extensively studied bibenzyl marchantin A, it is clearly evident that the presence of hydroxyl groups at $\mathrm{C} 1$, and C6' positions are significantly contributing in free radical scavenging and cytotoxic activities of the compound. The DPPH assay and structural conformational study further demonstrated that due to the absence of hydroxyl group at the $\mathrm{C}-6$ position in marchantin $\mathrm{C}$, it exhibited less antioxidant activity [32]. Another important observation is that the introduction of hydroxyl group at C-7' position or C-7, C-8 unsaturation could dampen the nitric oxide inhibition activity and possibly due to that structural difference in the trimethyl ether derivatives of marchantin A and B, they are less potent than the parent molecule [28].The inhibitory activity, radical scavenging property and therapeutic efficacy of any plant derived botanical could be detected easily in-vitro by different enzymatic assays (lipoxygenase, peroxidation, cyclooxygenase etc.). SAR study has revealed the substitution pattern of different bibenzyl compounds are responsible for primary inhibition. In case of 5-lipoxygenase, the inhibitor molecule requires at least two functional groups to react with enzyme's active site as well as to show lipophilicity. According to the structural information on marchantin $\mathrm{A}$, the catechol moiety in ring $\mathrm{C}$ and the phenolic hydroxy group in ring $\mathrm{A}$, are mainly responsible for enzyme inhibition. Similar pattern has been observed in marchantin $\mathrm{B}$ and radulanin $\mathrm{H}$ but in marchantin $\mathrm{D}$, presence of hydroxyethyl bridges reduces the efficacy. Moreover, two catechol moieties and absence of cyclic bis(bi)benzyl ring has critically enhanced similar bioactivity in paleatin B and perrottetin D. Acyclic structure has helped the first compound to get fit within the active site of the enzyme and stabilized its lipophilic chain too [64]. These peculiar patterns of lipophilicity are very useful to describe antioxidant activity, semiquinone radical formation and cytotoxicity exhibited by bibenzyls. In addition, perrottetin D acts as a phenolic antioxidant and forms a pyrogallol-type radical even at room temperature [64]. In pharmacological activity related section we have mentioned nitric oxide inhibition activity of bibenzyl and bis(bi)benzyls, isolated from $R$. appressa. Their efficacy has been tested on lipopolysachharide induced RAW 264.7 cell line and strikingly all the tested compounds were almost as potent as L-N6 -1-iminoethyl)lysine, the control. The important observation was both prenylated bis(bi)benzyls and bibenzyl-cannabinoids (radulannin A, radulannin L, 2geranyl3,5-dihydroxybibenzyl, 2(S)-2-methyl-2-(4-methyl-3pentenyl)-7-hydroxy-5-(2-phenylethyl), $O$-cannabichromene, 6-hydroxy-4-(2-phenylethyl) benzofuran and o-cannabicyclol) have shown strong antioxidant activity [28, 125].

Bibenzyls are reported for many other activities too. The thalloid liverwort, Blasia pusilla derived cyclic bis-bibenzyl dimers are responsible for plant growth inhibition whereas plagiochine A derived from Plagiochila sciophila showed neuritic sprouting and enhanced choline acetyl transferase activity [57]. Marchantin A and its trimethyl ether exhibited ameliorating effect against nicotine induced muscle contraction in mice model which was comparable with the standard drug d-tubocurarine. According to the researchers, due to the absence of nitrogen atoms, structural similarity with the active muscle relaxing drugs, presence of an $o$-hydroxyl group in 
marchantin A and an $o$-methoxy group in marchantin A trimethyl ether exhibited muscle relaxation activity [57, 63, 139]. Presence of phenolic hydroxyl group with benzene ring has been detected in another important compound, isoplagiochin A. Apart from this there is ether linkage and biphenyl bond present in isoplagiochin A, B and in all plagiochin-type bisbibenzyls isolated from Plagiochila sciophila Nees ex Lindenb. [28, 36, 125]. Significant cardioprotection and other biological role rendered by bibenzyl riccardin $\mathrm{C}$ and its $O$ methyl derivatives (riccardins $\mathrm{A}$, riccardin $\mathrm{F}$ etc.) were noted due to the presence of phenolic hydroxyl groups as well as C-1, C-2' and C-14, C-11' diaryl ether bonds, in their structure $[35,40]$. Halogenated natural products are common among marine organisms [54]. Similarly, in bibenzyl and bisbibenzyl compounds, the presence of halogen molecule is quite regular in occurrence. In bazzanin A (6'- chloro isoplagiochin C) desorption chemical ionisation (DCI)-MS has determined the presence of chlorine atom in the benzene ring along with the phenolic hydroxyl groups and two benzylic methylene. Similar structural conformation was noted in bazzanin B (6', ', - dichloro isoplagiochin C), bazzanin C $\left(6^{\prime}, 8^{\prime}, 12\right.$-trichloro isoplagiochin $\mathrm{C})$, bazzanin $\mathrm{D}\left(6^{\prime}, 8^{\prime}, 10^{\prime}\right.$-trichloro isoplagiochin C), bazzanin E $\left(6^{\prime}, 8^{\prime}, 10^{\prime}, 12\right.$-tetrachloro isoplagiochin C), bazzanin $\mathrm{F}\left(6^{\prime}, 8^{\prime}, 10,14^{\prime}\right.$-tetrachloro isoplagiochin $\left.\mathrm{C}\right)$, bazzanin $\mathrm{G}\left(2,6^{\prime}, 8^{\prime}, 10,10^{\prime}\right.$-pentachloro isoplagiochin $\left.\mathrm{C}\right)$, bazzanin $\mathrm{H}$ $\left(6^{\prime}, 8^{\prime}, 10,10^{\prime}, 14^{\prime}\right.$-pentachloro isoplagiochin $\left.\mathrm{C}\right)$ and bazzanin I $\left(2,6^{\prime}, 8^{\prime}, 10^{\prime}, 12,14^{\prime}\right.$-hexachloro isoplagiochin $\left.\mathrm{C}\right)$ detected by high resolution MS, proton-proton and proton-carbon shift correlated 2D experiments, NMR analysis. Bazzanin J or 6', 12-dichloroisoplagiochin $\mathrm{D}$ is the chlorinated derivative of isoplagiochin D, which was reported from Plagiochila fruticosa Mitt. [49]. The "fitting and chelating model" mediated structural contribution potentiated in-vitro PA endonuclease inhibitory activity of riccardin D, marchantins A and plagiochin A where the presence of 3,4-dihydroxyphenethyl group in structural moiety played the key role against $\mathrm{H} 3 \mathrm{~N} 2$, H1N1 influenza A and B viruses during the evaluation of more than 33 different types of phytochemicals [76]. Structural conformational study conducted through systematic unbounded multiple minimum search and NMR indicated the mobility of macrocyclic rings of riccardin A and marchantin A. It is assumed that the mobility of the former one is more restricted due to the introduction of the biphenyl linkage to the macrocyclic ring. This structural feature also evidenced for the reduced affinity of riccardin A towards calcium ions when calcium inhibitory activity was compared between these two macrocyclic bibenzyls at $\mathrm{ID}_{50}$ value 1.85 and $2.0 \mu \mathrm{g} / \mathrm{ml}$ [126]. Wide range of bioactivities like antibacterial activity against gram-negative and positive bacteria, growth inhibition against Mycobacterium tuberculosis, M. avium and M. noccardia, and enzymatic inhibition of 5-lipoxygenase and calmodulin activity could be interpreted by mode of action based on calcium-ion binding. The inhibitory role played by marchantin $\mathrm{C}$, isoplagiochins $\mathrm{A}$ and $\mathrm{B}$ against tubulin polymerization was tentatively attributed on the restricted biaryl ring system which is favourable for tubulin binding. These bibenzyls with two aromatic rings connected by a twocarbon bridge with a double bond also function as potent antitumor agent $[29,42,43,88]$. The structural and therapeutic similarity of marchantin A and isoquinoline alkaloid, cepharathine is mostly due to a common receptor binding phenomenon [86, 87]. Macrocyclic marchantins A and E are also able to activate the nuclear-receptor farnesoid X-receptor (FXR) required to control critical gene expression in bile acid and cholesterol homeostasis up to a level comparable with the chenodeoxycholic acid [39]. Not only the presence of phenolic groups but also its active binding to the aromatic ring system is necessary for functional state of bibenzyls. DHA, an antifungal agent extracted from Asterella angusta, enhanced adriamycin cytotoxicity in drug resistant K562/A02 cells but in DHA derivatives, where phenolic groups were methylated, reversal fold of compounds were weaker [52]. Phytochemical investigation of the ethyl acetate extract of the leaves and the stems of Bulbophyllum kwangtungense Schlecht., has revealed the presence of two novel stilbenoids, as confirmed by repeat column chromatography as well as 2D-NMR spectroscopic analyses. These compounds were characterized as 5-(2,3-dimethoxyphenethyl)-6methylbenzo[d][1,3] dioxole, and 10,11-dihydro-2,7dimethoxy-3,4-methylene-dioxy dibenzo[b,f] oxepine. The most striking part of this discovery is the identification of a natural bibenzyl compound with methyl group in the benzene ring, which is a very rare phenomenon. These compounds are also known as natural oxepines. Though reports on the isolation of such phytochemicals from natural sources are very rare, but till date most of them were reported for their potential anti-tumor activities. However, anti-tumor activities of the new compounds were also determined in vitro against Hela cells and the second compound showed significant cell growth inhibition with $\mathrm{IC}_{50}$ value of $47.2 \mu \mathrm{g} / \mathrm{ml}[83,123]$. Researchers have found the differences between NMR shift data of sesquiterpene and bisbibenzyl are due to the 'shielding' or 'deshielding' mechanism on aromatic rings of the bis(bi)benzyls by some protons of the sesquiterpene moieties which provide great challenge in force field parameterization as well as in extensive conformational analysis and molecular modelling of bibenzyls $[66,86,126]$. In addition, primary selection of natural products as potent future drug is done via molecular docking and ligand matching. In this process, by using in-silico tools and knowledge of stereochemistry the compounds are critically analysed to calculate their probability of being an active drug. The example of marchantin $\mathrm{C}$ is important in this context as the chemical structure of this macrocyclic bis(bi)benzyl is structurally similar to combretastatin A-4 (CA-4). CA-4 is a popular dihydrated dimer which is already reported as a vascular 
tumor targeting agent due to its potent microtubule polymerization inhibitory role $[140,141]$. Inhibition of microtubule polymerization, cell cycle arrest at $\mathrm{G} 2 / \mathrm{M}$ phase and halt in mitosis progression have been mediated by marchantin $\mathrm{C}$ in A172 and HeLa cells possibly due to the presence of bibenzyl skeleton and methoxy group [43]. The elucidation of tubulin binding mechanism of bis(bi)benzyls at the molecular level has revealed that the tubulin has three ligand binding sites namely colchicine, Vinca alkaloid, and taxane [142, 143]. The taxane binding site is for depolymerization of microtubules but if any antimitotic compound gets attached to Vinca alkaloid or colchicine binding site they do inhibit the polymerization of microtubules. CA-4 binds to the colchicine binding site [144-146]. Therefore, it can be assumed that bis(bi)benzyls which are structurally similar to CA-4, might also get attached to the colchicine binding site to block microtubule polymerization. Further study has also indicated the role of hydroxyl group in strong hydrogen bond mediated interaction between tubulin and bibenzyl compound and introduction of any halogen atom, as observed in riccardin D, alters the electron distribution and potentiates stronger hydrogen bond formation [16]. Backbone conformation is another important feature of any potent antimitotic agent. It was reported that the presence of two aromatic rings and their attachment through the double bond contribute in ideal backbone conformation which can be observed in case of marchantin class of bibenzyls [42]. Apart from studying the modes of action of anti-cancer activity of bibenzyls, the inhibitory role of marchantin E against influenza PA endonuclease activity was also analysed by researchers. In this case in silico docking simulation process is used to decipher the role of dihydroxy phenethyl group. The experimental data clearly demonstrated that the dihydroxy moiety present in dihydroxy phenethyl group of marchantin E actually chelates the $\mathrm{Mn}^{2+}$ ions present in active site of PA endonuclease and as a result marchantin $\mathrm{E}$ gets well anchored to the active site of the enzyme via some hydrophobic interaction [140, 141, 147, 148]. Moreover, conserved amino acid domain of Arg84, Asp108, Glu23, Glu80, Glu119 His41, and Lys134, in influenza virus A and B actually aid in PA endonuclease inhibition as showed by marchantin E [76]. Riccardin $\mathrm{C}$ which have shown antiMRSA activity have shown presence of phenolic hydroxyl group and the 2-phenoxyphenol moiety is essential for such activity but confirmation of particular molecular target is yet to be done [149].

\section{Critical appraisal of medicinal property and underlying mode of action of important bibenzyls}

The series of papers and book chapters published by Asakawa and group for over a decade, largely emphasized the application of bryophytes and its phyto-chemical constituents to act as pharmaco-therapeutic natural product $[1,4,7,12,14$, $36,47,139]$. The presently available data on chemical diversity of bryophytes indicated the presence of numerous bioactive terpenoids, sterols, essential oil, fatty acids, alkanones and other aromatic compounds such as bibenzyls and bis(bi)benzyls. However, in the present review work, we have tried to streamline the biomedical application of bibenzyls and its derivatives. In natural products based research, the first stage of screening bioactivity of any compound (isolated and characterized already) is in-vitro and/or in-vivo experiments, which may further be supported by different enzymatic assays. It is quite evident that lots of in-vitro studies have indicated cytotoxic efficacy of bibenzyls and bis(bi)benzyls [1, 19, 32, 41, 51, 53, 66]. However, less number of compounds, were screened under the second phase which includes proteininteraction, similarity based sequencing, moiety based molecular docking etc. For very few compounds SAR based information is available i.e. marchantins A, B, E [28, 61, 125], riccardin A [126], 14-Hydroxylunularin [26] and data available on third and fourth stage of trials is quite limited. Interestingly, almost 35 years back, in 1985, synthetic nonsteroidal, poly-fluorinated bibenzyl drug, bifluranol (trade name prostarex) went through human trial for its antiandrogenic properties against benign prostatic hyperplasia. After completion of 12 weeks study period in double blind trial, 35 patients suffering with bladder outflow obstruction, exhibited improvement in urinary flow and frequency ( $\mathrm{p}$ $<0.05$ )when compared to diethylstilbestrol [117]. The compound was previously reported for anti-fertility activity in mice and rat models [150].

Bryophytes, especially the liverworts and mosses, have been reported for their allelopathic and anti-microbial properties. In many cases, presence of selective chemicals insisted strong odor which helped bryophytes to serve as repellant. The table 1 clearly illustrated many of the bibenzyls and bisbibenzyls are reported for anti-microbial activity. In case of antifungal most of the experiments were performed against C. albicans. However, a large variety of bacteria were studied to ensure anti-bacterial efficacy of this natural product. Currently, emergence of strain VISA (vancomycin-intermediate-resistant Staphylococcus aureus) and MRSA (methicillinresistant Staphylococcus aureus) have shown MDR feature under clinical investigation and incurred threat to community-acquired infections (CAI) [149]. The bisbibenzyls isolated from bryophytes, exhibited anti-MRSA bactericidal activity towards these pathological strains. It is further noted, that leakage of cell membrane and/or formation of mesosome in S. aureus N315 are responsible for such antibacterial activity of riccardin type phenolic components when compared with vancomycin [151]. The study of cellular eflux of ethidium bromide (fluorescent DNA-binder) or enhanced intracellular gradient of $\mathrm{Na}+$ and reduction of concentration of 
$\mathrm{K}+$ could indicate clearly how this anti-MRSA activity is manifested in this gram positive bacteria [152]. Plagiochin class of compounds with different $\mathrm{C}$-ring linkages provided variable data on molecular dynamics based calculations and clearly indicated conformational flexibility determines the extent of bacteriocidal efficacy [152]. Riccardin C exerted antiMRSA activity against strain OM584 and OM481 with MIC value of $3.2 \mu \mathrm{g} / \mathrm{ml}$ when compared with standard ZYVOX or linezolid [149].

However, if we dig deeper, presence of similar compounds is indicative of its efficient cytotoxicity. The mechanism of such anti-proliferative activity is variable but DNA polymerase inhibitory activity is important one among them. It is noteworthy, that the popular anti-cancer alkaloid of Catharanthus roseus, vincristine, which is marketed as "vindesine", function as DNA polymerase inhibitor [153]. Such Vinca alkaloids are microtubule destabilizers and critical target in oncotherapy but their drug resistance, systemic toxicity, complex and expensive synthesis, poor rate of bioavailability limited cost-effective application [16]. In anti-HIV-1 activity exhibited by marchantins A, $\mathrm{B}, \mathrm{D}$, paleatin $\mathrm{B}$ and perrottetin $\mathrm{F} ; \mathrm{IC}_{50}$ value ranged from 5.3 $\mu \mathrm{g} / \mathrm{ml}$ to $23.7 \mu \mathrm{g} / \mathrm{ml}[137,154]$. These compounds showed activity against TIBO-resistance HIV-1 reverse transcriptase [85]. The enzymatic inhibition strategy is often at par with different biological activities. Scientists have reported calmodulin and 5-lipoxygenase inhibition in marchantins $\mathrm{D}, \mathrm{E}$, perrottetins A, D and riccardin A ( $\left.\mathrm{ID}_{50} 2.0-95.0 \mu \mathrm{g} / \mathrm{ml}\right)[7,8$, 56], Cyclooxygenase inhibitory activity was also demonstrated by perrottetin $\mathrm{D}$, radulanin $\mathrm{H}$, paleatin $\mathrm{B}$, marchantins $\mathrm{A}, \mathrm{B}, \mathrm{E}$ with respective $\mathrm{IC}_{50}$ values as $26.2,39.7,45.2,46.4,55.9$ and $58.0 \mu \mathrm{M}$ [64]. It is important to note, among naturally originated drugs acetylsalicylic acid (semi-synthetic form of salicylic acid) act as cyclooxygenase inhibitor [153]. The tyrosinase inhibition is another important aspect. The bibenzyl xyloside compounds isolated from Chlorophytum arundinaceum Baker (Liliaceae) and some chemically synthesized compounds derived via Wittig reaction from 2,4-dihydoxybenzaldehyde, also reported such activity $\left(\mathrm{IC}_{50} 1.6 \mu \mathrm{M}\right)$ when compared with kojic acid $[155,156]$. These indicates future direction of similar investigation could yield positive result when performed with bibenzyls from bryophytic origin. In the year, 2009, the pandemic, caused by H1N1 and H5N1 influenza virus compelled scientist all over the world to search for novel anti-influenza lead from nature. During such screening, Iwai et al., 2011, first time reported liverwort based bibenzyl compounds, plagiochin A and marchantins A, B, E could inhibit activity of influenza A endonuclease which can be of significant importance [76].

Apart from SAR studies various mode of action revealed anti-cancer properties exhibited by bibenzyls and their derivatives. For DHA, its induction of autophagy and apoptosis was observed in human U2OS cells. The formation of autophagic vacuole, elevated level of LC3-II autophagy protein marker, p53 phosphorylation, up-regulation of p21Waf1/
Cip1 (p53 target gene) are all the parts of this autophagic induction. Moreover, reduction of cyclin B1 expression caused cell cycle arrest at G2/M-phase which is another part of apoptotic mechanism exerted by DHA, but complete elucidation of $\mathrm{p} 53$ signaling pathway regulation and modulation of nuclear and cytoplasmic functions of p53 is still incomplete [53]. For marchantin A induced apoptosis of MCF-7 cell line, the mechanism is regulated by caspase-dependent pathway. The decreased expression of cyclin proteins (cyclin B1, cyclin $\mathrm{D} 1, \mathrm{p} 21, \mathrm{P} 27)$ halted the progression of cell cycle through $\mathrm{G} 0$ / G1 phase $(<5 \mathrm{lg} / \mathrm{ml}$ dosage $)$ or at $\mathrm{G} 2 / \mathrm{M}$ phase where $7.5-10.0$ $\mu \mathrm{g} / \mathrm{ml}$ marchantin A had been applied. The structural and functional similarities of marchantins $\mathrm{A}$ and $\mathrm{C}$ as well as the presence of aromatic ring at C-10 and C- 6 potentiated them as ideal chemotherapeutic agents [32]. In recent times, hormone resistant prostate tumors emerged as critical challenge to the oncologists. It could be noted, in therapy of prostate cancer, application of bis(bi)benzyl at low concentration $(<10 \mu \mathrm{M} / \mathrm{L})$ suppressed androgen receptor signaling in LNCaP cells which is essential for cell viability [77]. Over-expression of topoisomerase II plays critical role in proliferation of endothelial cancer cells [157-159]. Riccardin D mediated antiangiogenesis also involves suppression of many angiogenesis-promoting factors EGF, VEGF mitogen, VEGF receptor and MMPs [160] as studied in HUVEC cell line [90]. The upregulation of VEGF expression triggers oncogenic mutations, vascular endothelial cell proliferation, enhances vascular permeability which ultimately resulted in tumorogenesis. However, the inhibition of DNA topoisomerase II, has been found in riccardin D pretreated HL60, K562 and MDR resistant K562/A02 cell line. Interestingly, antimitotic agent podophyllotoxin which is marketed as semisynthetic drug etoposide also works on principle of DNA topoisomerase II inhibition [153]. Oxidative stress is closely assisted with Parkinson's disease related neurodegeneration. Some bibenzyls isolated from the Orchidaceae family exerted reversal of neurotoxicity. However, the bibenzyl compound, chrysotoxine, prevented 6-hydroxydopamine (6-OHDA) induced cytotoxicity in SH-SY5Y human neuroblastoma cell line, inhibited NF-kB translocation, blocked iNOS upregulation and reduced intracellular nitric oxide (NO) level significantly. These modulations suggested probable efficacy of chrysotoxine as psycho- active drug [161]. Plagiochin E mediated cytotoxicity that relies on metacaspase signaling pathway included G2/M cell cycle arrest, chromatin condensation, cytochrome c release, nuclear fragmentation, and phosphatidylserine exposure. Release of cytochrome c, CDC28, CLB2, CLB4 over-expression and ROS accumulation caused metacaspase activation and triggered apoptosis in C. albicans [83].

The features which are generally involved with cancer chemotherapy are reduced drug accumulation, low uptake and high efflux, broad distribution, reversal of drug resistance, 
DNA repair, and prevention of tissue damage, cell-cycle regulation, apoptotic induction and maintenance of signaling pathways [162]. There are many research reports which indicated tumors are achieving resistance against broad spectrum of chemotherapeutic drugs. Therefore, MDR reversal is another critical property of chemotherapeutic drug designing. Most significantly introduction of MDR is triggered by overexpression of ATP binding cassette (ABC) transporter proteins. However, among these, transmembrane glycoprotein (P-gp), one ATP-dependent drug transporter, which carries drug molecule out of the cell and thus lowers intracellular accumulation and increases drug efflux, is considered as potential candidate for reversal of multidrug resistance [52]. DHA and many of its derivatives and other bibenzyl compounds also showed similar multidrug resistance reversal in chemo-resistant cancer cells $[41,51]$. If we look into other activities, riccardin D synergistically acted against in vitro growth of $C$. albicans, and reverted fluconazole resistance. It is assumed that riccardin D interfered with the fluconazole-targeted ergosterol biosynthesis pathway [41,53]. On the other hand, riccardin $\mathrm{C}$ acted as a cardioprotective agent as it was found to increase plasma HDL level in mice without altering concentration of triglyceride. It promoted cholesterol efflux (THP-1 cell line) and could be counted as promising anti-obesity natural product [58]. In search of relation between chemical diversity of natural products and their functionality it was found that cyclotheonamide A targeted thrombin protein [153] and similar screening was done on perrotetin $\mathrm{E}$ which was an important cardioprotective agent [81].

The class bibenzyl cannabinoids are already reported for their psycho-therapeutic and other bioactivities and in the section "Bibenzyl cannabinoid: therapeutically most studied derivatives of bibenzyls", we have discussed the importance of Radula genus in this aspect. However, cannabinoid moiety based synthetic drugs which acts on cannabinoid receptors type 1 (CB1) and 2 (CB2) are potential lead for modern drug discovery and $\Delta 9$-tetrahydrocannabinol is one such important candidate. The authors have mentioned structural similarity of $\Delta 9$-tetrahydrocannabinol (from $C$. sativa) with $\Delta 1$-tetrahydrocannabinol (from Radula sp.). So, the principle of mechanism may be applied to both types of compound or other types of phytocannabinoids. Moreover, the endocannabinoid system associated with endocannabinoid metabolizing enzymes could modulate lots of physiological responses and various in vivo, in vitro, in silico screening of therapeutic application have further supported that claim. The study for natural cannabinoid ligands has been performed in angiosperms but in bryophytes similar studies are extremely few [163].

Bioprospecting of unexplored natural sources is critical in modern research as it ensures not only identification of target protein but also accelerates detection and standardization of new drugs. The appraisal of bibenzyl oriented synthetic chemistry has clearly pointed out the presence of chiral isomers free of stereogenic carbons and conformational variability due to positional difference of C-ring, is highly crucial for biological activity. Highly-classified synthesis model analysis manifested role of Wittig and other related reactions in cost-effective (yield-wise) synthesis of broad spectrum bibenzyl and bis(bi)benzyl compounds [164]. Professor Y. Asakawa mentioned identification of 103 bibenzyls from liverwort which are synthesized by dimerization of lunularic acid in his number of papers $[1,165,166]$. However, revelation of functional prospects or critical analysis of underlying mechanism of action of any bioactivity is highly required to categorize the natural products on the basis of their application. Structural characterization or chemical screening is closely correlated with that phase. It is noted by Tulp and Bohlin, that large number of structure-wise different chemical compounds, may or may not be isolated from distantly related organism could fall into the same functional category [153]. Further, genome wide sequencing or molecular modeling or screening of protein-protein interaction could reveal how their structural characters are enhancing or reducing some activities. This categorization and identification of natural products based on functional versus chemical diversity helps scientists to understand which natural product are suitable for drug mimicking based screening and why. In this article we discussed medicinal activities of bibenzyl type of compounds in light of their mode of action. The mechanism based similarity of some standardized drugs, already available in market, are also mentioned. These findings will aid in understanding the potential of bibenzyl in future pharmaco-therapeutic research.

\section{Research insights on bryophyte derived bibenzyls; past present and future}

Investigation of natural products is an integral part of modern research and obviously for ancient land plants like bryophytes such systemic investigation is highly essential to establish the chemo-taxonomical database and to interpret their physiology and cellular metabolism. For millions of years, the phytochemicals, including aromatic complex molecules like bibenzyls and bisbibenzyls, are playing the role of 'survival key" to enable them to sustain under broad habitat zone (i.e. polar, arctic, and boreal). The occurrence of bibenzyls in algae, bryophyte, pteridophyte, and orchids has intrigued interest among researchers to establish chemical inter-relationships on point of evolutionary pattern of phytochemical linkage [1, $36,128,139,167]$. Natural product oriented bioprospecting has also indicated convergent evolution of bryophytes [105, 124]. Researchers have found surprising functional similarity of MADS box transcription factor (type II) or MIKC class gene in evolutionary distant groups. In seed plants they are contributing in flower development whereas in non-seed plants they are regulating sporophytic and gametophytic 
alteration of generation [168]. In future, such insights into evolutionary pattern could illuminate any phytochemistry oriented study of any plant lineage. So, to understand the complex metabolic pathway leading to bibenzyl production, both in non-seed plants and flowering plants; or to determine which stage of development is triggering the secondary metabolite accumulation; the genome specific molecular interpretation is highly recommended. Scientific interpretation of their taxonomical lineage, ecological adaptations, anatomical development or chromosomal evolution from fossil study of this primeval land plant has been challenging for a long time. Even nowadays, bryophyte oriented research, in terms of pharmacological, biochemical or molecular analysis, is significantly low around the globe. Considering its role as pollution indicator, toxin-accumulator or "nutrient redistributor" [169] the plant lineage demands more attention from modern research.

Over the last two decades, advent of modern qualitative high-end tools like; high performance TLC, high performance liquid chromatography (HPLC), Fourier transform infrared (FTIR) spectroscopy, gas chromatography (GC)-MS, NMR, matrix-assisted laser desorption/ionization, liquid chromatography with diode array detection (LC-DAD), X-ray crystallography etc. has contributed broadly in phytochemical research. Along with qualitative and quantitative analytical research, the application of bio-informatics, molecular docking and functional moiety based similarity-studies have contributed greatly in identification of functional leads in drug discovery. In recent times, eco-metabolomics emerged as a novel subject where interaction of ecological and biochemical features are studied as well as correlated. Recently, computational workflow based data interpretation model was applied to understand seasonal variability of secondary metabolite content in bryophytes [170]. In future such research output may pave ways for illustration of plant metabolomics and their mode of action. Eminent bryologist Asakawa and his collaborators are doing fantastic research on bryophytes and pharmaco-active properties of bibenzyl and bis(bi)benzyl type of compounds. In one of his book chapter [4], the total procedure of collection, extraction, distillation procedure, TLC, HPLC, GC-MS, use of solvents, purification steps were clearly mentioned. Nowadays, qualitative variation of active phytochemicals due to altitude, season of growth and tissue type of mother plant could be detected quantitatively using these cutting-edge techniques. In this context, one could consider the prospects of maintaining bryophytic in-vitro culture to ascertain production of novel and medicinally expendable botanical products [171]. Biotransformation could also be of similar significance [172], where fungi Aspergillus niger (TBUYN-2) and Neurospora crassa converted marchantin A into 10-hydroxymarchantin A, 3'-hydroperoxymarchantin A and 5'-hydroperoxymarchantin A. The axenic culture is another reported method which can be useful in extraction of medicinally valuable bibenzyls and bisbibenzyls under laboratory condition. This method has been employed on M. polymorpha for extraction of marchantin A [173]. Emergence of such novel strategies and revelation of genomic data of non-seed plants holds the future strategic key for next level investigation of bibenzyl and bis(bi)benzyl molecules isolated from large number of bryophytes.

\section{Discussion}

Bryophytes are reported from almost all parts of the world yet a little is known about their chemistry and to be exact, among all classes of bryophytes only the mosses and liverworts were examined critically. However, there are several examples, related to terpenoids, phenolics, biflavones, stilbenoids-bibenzyls etc. which demonstrate the unique phytochemical richness of bryophytes. Presently, natural products, their synthetic and semisynthetic analogs are playing vital role in drug discovery [163]. The present article provides multi-directional views deeply assisted with bibenzyl oriented research, their structure-function wise diversity and future application of the screening endeavor. In this review, we have provided insight on classical topics like ethnobryology; summarized pharmacological properties of large number of bibenzyl and their derivatives; included ongoing research status on bibenzyl cannabinoids as well as bibenzyls extracted from Orchidaceae family; discussed various aspects of SAR, mode of action and research insights; critically analyzed potential of bibenzyl type of molecule as therapeutic lead component and tried to assess the overall impact of bibenzyl and bisbibenzyls extracted from bryophytes. However, we have noted some ambiguity also. Marko et al., 2017, reported ethnomedicinal property, chemical constituents and pharmacological activity of 52 bryophytes belonging to 20 families of liverwort and 13 families of mosses [137]. Though this paper elaborately described all these aspects but it was not clearly mentioned how biochemical compounds, isolated from all these bryophytes, contributing in reported bioactive property of the same. A number of bibenzyl and bis(bi)benzyl types of compounds have been isolated, characterized and pharmacologically tested till date but there are large numbers of compounds present which are not evaluated for their probable medicinal application. In this review, the authors have clearly mentioned different bibenzyls and their derivatives and presented available data on bioactivity-based investigation. The authors have also observed, for some bioactivity the reported articles are describing variable outcome. The liverwort sensitivity (as determined by patch test) and the relation of these bryophytes with allergic contact dermatitis. The six species of Frullania were described but this paper not mentioned any protective role of bibenzyl against acute dermatitis [174]. However the role of sesquiterpene lactones, especially frullanolide as sensitizer in this context was noted. On the other hand, the similar activity of 4-hydroxy-3'-methoxybibenzyl act against dermatophytic fungi Trichophyton mentagrophytes 
was already reported [97]. Similarly M. polymorpha was reported for allergic contact dermatitis but the identification of allergens is still not completed [58]. In some cases, many bioactivities were represented as unpublished data [58] which has filled such claims with some ambiguities. According to previous report, a large number of bryophytes Plagiochilafruticosa, P. ovalifolia, Bazzania pompeana, Porella caespitans, Marsupella emarginata, Radula perrottetii etc, were examined as cytotoxic against P-388 in crude ether extract form but such claim was not validated in later days by further investigations. But on other hand, Prof. Asakawa's claim on chemopreventive compound isomarchantin $\mathrm{C}[1,34,58]$ as potent inhibitor of cathepsin $\mathrm{L}$ $\left(95 \%\right.$ inhibition at $\left.10^{-5} \mathrm{M}\right)$ and cathepsin B $(93 \%$ inhibition at $10^{-5} \mathrm{M}$ ) activity were proved [1]. Interestingly, in his two major reviews, Prof. Asakawa described different aspects of phytochemical activity isolated from bryophytes in a very similar manner $[1,58]$. However, we have tried to focus mainly on bibenzyl type of compounds. In natural product based research proper identification and authentication of study material are highly important. However, in some older paper $[175,176]$ we have noticed taxonomic validation part is absent.

The traditional reports or preclinical and clinical studies have also supported myriads of medico-therapeutic properties of bryophytes such as anti-pyretic, anti-arthritic, antituberculosis, anti-hematemesis, anti-dermatomycosis, antipneumonia,anti-hepatic and wound-burn-fracture healing properties. Mostly the marchantin-type bibenzyls were investigated; but it could be observed, that the other types of bibenzyls and bis(bi)benzyls are also pharmacologically important. However, critical evaluation of cited references revealed bibenzyl compounds are mostly studied on both in-vitro cell lines and in-vivo experimental organisms, for cytotoxic or anti-proliferative properties, along with various structure-function studies. Apart from in-vitro or invivo cytotoxic assays, growth inhibition studies (anti-bacterial, anti-fungal, anti-viral, anti-trypanosomal, antifeedant, nematocidal) of bibenzyl and its derivatives, were also conducted by many researchers. However, lack of proper standardization protocol, unavailability of pharmacological data of structurally characterized compounds, difficulty of identification, collection and maintenance of bryophytes played delimiting role in bryophyte-originated bibenzyl related research. Similar phenomenon could be observed for bibenzyl cannabinoids isolated primarily from different species of genus Radula. Notably, Radula preparations are also popular as "legal-high" due to high cannabinoid content [105]. The cannabinoids, (extracted from C. sativa and other angiosperms), extensively studied for psycho-active efficacy but the natural compound perrottetinene acid and its decarboxylated form perrottetinene, (harvested from bryophyte), have not been studied well and thus their pharmacological applications are not validated scientifically [103].

\section{Conclusion}

The approaches towards phytochemical data-mining are integral part of future drug development program including detection, isolation, characterization, structure conformation, therapeutic evaluation, quality control, determination of bioactive mechanism and in-silico drug designing from these novel active chemical group of bibenzyls from bryophytes. Assessment of this potent chemical group is the essential part of widening the sector of complementary and alternative medicines and natural product derived nutraceuticals and dietary supplements. Under in-vitro or in-vivo studies, the tested chemical is applied on micromolecular level but in most of the cases, the inter-molecular interaction, pharmacokinetics or stoichiometric calculation, toxicity and lethality determination are not fully defined. Before recommending bibenzyl compounds as potent chemotherapeutic agent or exploiting its multi-array of SAR in drug designing, all these knowledge-gap must be filled. What could be the possible application of bibenzyl cannabinoid isolated from bryophytes? how it can stimulate endocannabinoid system? what role its special structural moiety is playing? what possible role bibenzyls could play as cytotoxic agent? what is the probable chances of marchantin-group of bibenzyl to emerge as potential therapeutic lead? all these answers must be answered and validated. Exploitation of MDR reversal, cellular toxicity, growth inhibition or every other possible bioactive window must ensure costeffectiveness as bryophytes are morphologically insignificant and hard to identify. The labor-intensive, complex extraction and characterization of natural products are often not met with expected outcome under in-silico screening. Moreover, lacunae of mode of action often delays higher stages of experimental approaches for any natural product. However, the descriptive review has covered bryophyte originated bibenzyl research in some unexplored areas. Similar research, would therefore, elaborate knowledge about bryophytes as novel source of therapeutically active natural products and the role of bibenzyl and bis(bi)benzyl compounds as potential lead molecule of pharmaceutical importance would be understood in a better way.

Author's contribution SN prepared the manuscript, tables and figure 2. $\mathrm{AD}$ contributed in language correction, critical editing, prepared figure 1 and contributed photograph of bryophytes (figure 1, G and $\mathrm{H}$ ) from his personal photography collection.

Funding information SN thankfully acknowledge research grant provided by DST-INSPIRE (Fellowship sanction letter no. \& date: C/4588/IFD/ 2014-15 \& 25.11.2014). The corresponding author, AD, want to acknowledge FRPDF grant sanctioned by Presidency University, Kolkata.

\section{Compliance with ethical standards}

Ethical declaration No specific declaration is provided as this article is a review.

None of the authors have financial relationship with a commercial entity that has an interest in the content of this study. 
Conflict of Interest The authors declare that they have no conflict of interest.

\section{References}

1. Asakawa Y, Ludwiczuk A. Chemical constituents of bryophytes: structures and biological activity. J Nat Prod. 2017;81:641-60.

2. Wu XZ, Cheng AX, Sun LM, Lou HX. Effect of plagiochin E, an antifungal macrocyclic bis (bibenzyl), on cell wall chitin synthesis in Candida albicans 1. ActaPharmacolog Sin. 2008;29:1478-85.

3. Xie CF, Lou HX. Secondary metabolites in bryophytes: an ecological aspect. ChemBiodivers. 2009;6:303-12.

4. Asakawa Y, Ludwiczuk A. Bryophytes: Liverworts, mosses, and hornworts: extraction and isolation procedures. In: Metabolomics Tools for Natural Product Discovery. Totowa: Humana Press; 2013. p. 1-20.

5. Charron AJ, Quatrano RS. Between a rock and a dry place: the water-stressed moss. Mol Plant. 2009;2:478-86.

6. Dey A, De JN. Cytotoxic bryophytes: present status and therapeutic potential: a review. Asian J Trad Med. 2012.

7. Asakawa Y, Matsuda R. Riccardin C, a novel cyclic bibenzyl derivative from Rebouliahemisphaerica. Phytochemistry. 1982;21:2143-4.

8. Asakawa Y. Biologically active substances from bryophytes. CRC Press: Boca Raton; CAB Direct. 1990;259-87.

9. Shu YF, Wei HC, Wu CL. Sesquiterpenoids from liverworts Lepidoziavitrea and L. fauriana. Phytochemistry. 1994;37:773-6.

10. Toyota M, Kinugawa T, Asakawa Y. Bibenzyl cannabinoid and bisbibenzyl derivative from the liverwort Radula perrottetii. Phytochemistry. 1994;37:859-62.

11. Lu ZQ, Fan PH, Ji M, Lou HX. Terpenoids and bisbibenzyls from Chinese liverworts Conocephalumconicum and Dumortierahirsuta. J Asian Nat Prod Res. 2006;8:187-92.

12. Asakawa Y. Chemical constituents of the bryophytes. In: Progress in the chemistry of organic natural products. Vienna: Springer; 1995. p. 1-562.

13. Asakawa $\mathrm{Y}$, Hashimoto T, Takikawa K, Tori M, Ogawa S. Prenylbibenzyls from the liverworts Radula perrottetii and Radula complanata. Phytochemistry. 1991;30:235-51.

14. Asakawa Y, Ludwiczuk A, Nagashima F. Phytochemical and biological studies of bryophytes. Phytochemistry. 2013;91:52-80.

15. Zheng GQ, Ho DK, Elder PJ, Stephens RE, Cottrell CE, Cassady JM. Ohioensins and pallidisetins: novel cytotoxic agents from the moss Polytrichumpallidisetum. J Nat Prod. 1994;57:32-41.

16. Jiang J, Sun B, Wang YY, Cui M, Zhang L, Cui CZ, et al. Synthesis of macrocyclic bisbibenzyl derivatives and their anticancer effects as anti-tubulin agents. Bioorg Med Chem. 2012;20: 2382-91.

17. Lorimer SD, Perry NB, Tangney RS. An antifungal bibenzyl from the New Zealand liverwort, Plagiochilastephensoniana. Bioactivity-directed isolation, synthesis, and analysis. J Nat Prod. 1993;56:1444-50.

18. Baek SH, Phipps RK, Perry NB. Antimicrobial Chlorinated Bibenzyls from the Liverwort Riccardia $m$ arginata. J Nat Prod. 2004;67:718-20.

19. Scher JM, Speakman JB, Zapp J, Becker H. Bioactivity guided isolation of antifungal compounds from the liverwort Bazzaniatrilobata (L.) SF Gray. Phytochemistry. 2004;65:25838.

20. Niu C, Qu JB, Lou HX. Antifungal bis [bibenzyls] from the Chinese liverwort MarchantiapolymorphaL. ChemBiodivers. 2006;3:34-40.

21. Guo XL, Leng P, Yang Y, Yu LG, Lou HX. Plagiochin E, a botanic-derived phenolic compound, reverses fungal resistance to fluconazole relating to the efflux pump. J Appl Microbial. 2008;104:831-8.

22. Komala I, Ito T, Nagashima F, Yagi Y, Asakawa Y. New sesquiand diterpenoids from the liverwort Chandonanthushirtellus.In: 53rd Symposium on Chemistry of Terpenes, Essential Oils and Aromatics, Nara, Japan, Symposium Papers. 2009;266.

23. Komala I, Ito T, Nagashima F, Yagi Y, Asakawa Y. Cytotoxic, radical scavenging and antimicrobial activities of sesquiterpenoids from the Tahitian liverwort Mastigophoradiclados (Brid.) Nees (Mastigophoraceae). J Nat Med. 2010;644:417-22.

24. Komala I, Ito T, Nagashima F, Yagi Y, Asakawa Y. Cytotoxic bibenzyls, and germacrane-and pinguisane-type sesquiterpenoids from Indonesian, Tahitian and Japanese liverworts. Nat Prod Commun. 2011;63:303-9.

25. Labbé C, Faini F, Villagrán C, Coll J, Rycroft DS. Bioactive polychlorinated bibenzyls from the liverwort Riccardiapolyclada. J Nat Prod. 2007;70:2019-21.

26. Roldos V, Nakayama H, Rolón M, Montero-Torres A, Trucco F, Torres S, et al. Activity of a hydroxybibenzyl bryophyte constituent against Leishmania spp. and Trypanosoma cruzi: In silico, in vitro and in vivo activity studies. Eur J Med Chem. 2008;43: 1797-807.

27. Tamehiro N, Sato Y, Suzuki T, Hashimoto T, Asakawa Y, Yokoyama $\mathrm{S}$, et al. Riccardin $\mathrm{C}$ : a natural product that functions as a liver $\mathrm{X}$ receptor (LXR) $\alpha$ agonist and an $\mathrm{LXR} \beta$ antagonist. FEBS Lett. 2005;579:5299-304.

28. Harinantenaina L, Takahara Y, Nishizawa T, Kohchi C, Soma GI, Asakawa Y. Chemical constituents of malagasy liverworts, Part V: Prenylbibenzyls and clerodanediterpenoids with nitric oxide inhibitory activity from Radula appressa and Thysananthusspathulistipus. ChemPharmaceut Bullet. 2006;54: 1046-9.

29. Shi YQ, Liao YX, Qu XJ, Yuan HQ, Li S, Qu JB, et al. Marchantin C, a macrocyclic bisbibenzyl, induces apoptosis of human glioma A172 cells. Cancer Lett. 2008;262:173-82.

30. Xiao K, Zhang HJ, Xuan LJ, Zhang J, Xu YM, Bai DL. Stilbenoids: chemistry and bioactivities. In Stud Nat Prod Chem. 2008;34:453-646. Elsevier

31. Cheng A, Sun L, Wu X, Lou H. The inhibitory effect of a macrocyclic bisbibenzylriccardin D on the biofilms of Candida albicans. Biol Pharm Bull. 2009;32:1417-21.

32. Huang WJ, Wu CL, Lin CW, Chi LL, Chen PY, Chiu CJ, et al. Marchantin A, a cyclic bis (bibenzyl ether), isolated from the liverwort Marchantiaemarginata subsp. tosana induces apoptosis in human MCF-7 breast cancer cells. Cancer Lett. 2010;291:10819.

33. Asakawa Y, Ludwiczuk A. Marchantiophyta: bio-and chemical diversity and bioactivity. Malaysian J Sci. 2009;28:229-57.

34. Asakawa Y, Huneck S, Toyota M, Takemoto T, Suire C. Monoand sesquiterpenes from Porellaarboris-vitae. J Hattori Bot Lab. 1979:163-7.

35. Asakawa Y, Toyota M, Taira Z, Takemoto T, Kido M. Riccardin $\mathrm{A}$ and riccardin $\mathrm{B}$, two novel cyclic bis (bibenzyls) possessing cytotoxicity from the liverwort Riccardiamultifida (L.) S. Gray. J Org Chem. 1983;48:2164-7.

36. Asakawa Y, Toyota M, Tori M, Hashimoto T. Chemical structures of macrocyclic bis (bibenzyls) isolated from liverworts (Hepaticae). J Spectroscopy. 2000;14:49-75.

37. Zinsmeister HD, Becker H, Eicher T. Bryophytes, a source of biologically active, naturally occurring material. AngewandteChemie International Edition in English. 1991;30: 130-47.

38. Asakawa Y. Recent advances in phytochemistry of bryophytesacetogenins, terpenoids and bis (bibenzyl) s from selected Japanese, Taiwanese, New Zealand. Argentinean and European liverworts Phytochemistry. 2001;56:297-312. 
39. Suzuki T, Tamehiro N, Sato Y, Kobayashi T, Ishii-Watabe A, Shinozaki Y, et al. The novel compounds that activate farnesoid $\mathrm{X}$ receptor: the diversity of their effects on gene expression. $\mathrm{J}$ Pharmacol Sci. 2008;107:285-94.

40. Hioki H, Shima N, Kawaguchi K, Harada K, Kubo M, Esumi T, et al. Synthesis of riccardin C and its seven analogues. Part 1: The role of their phenolic hydroxygroups as LXR $\alpha$ agonists. Bioorg Med Chemistry Lett. 2009;19:738-41.

41. Sun B, Yuan HQ, Xi GM, Ma YD, Lou HX. Synthesis and multidrug resistance reversal activity of dihydroptychantol A and its novel derivatives. Bioorg Med Chem. 2009;17:4981-9.

42. Morita H, Tomizawa Y, Tsuchiya T, Hirasawa Y, Hashimoto T, Asakawa Y. Antimitotic activity of two macrocyclic bis (bibenzyls), isoplagiochins A and B from the Liverwort Plagiochilafruticosa. Bioorg Med Chem Lett. 2009;19:493-6.

43. Shi YQ, Zhu CJ, Yuan HQ, Li BQ, Gao J, Qu XJ, et al. Marchantin C, a novel microtubule inhibitor from liverwort with anti-tumor activity both in vivo and in vitro. Cancer Lett. 2009;276:160-70.

44. Anton H, Kraut L, Mues R, Maria IM. Phenanthrenes and bibenzyls from aPlagiochila species. Phytochemistry. 1997;46(6):1069-75.

45. Qu JB, Sun LM, Lou HX. Antifungal variant bis (bibenzyl) s from the liverwort Asterellaangusta. ChinChem Lett. 2013;24:801-3.

46. Toyota M, Yoshida T, Kan Y, Takaoka S, Asakawa Y. (+)Cavicularin: A novel optically active cyclic bibenzyldihydrophenanthrene derivative from the liverwort Caviculariadensa Steph. Tetrahedron Lett. 1996;37:4745-8.

47. Asakawa Y. Polyphenols in bryophytes: structures, biological activities, and bio-and total syntheses. Recent Adv Polyphenol Res. 2016;5:36-66.

48. Qu J, Xie C, Guo H, Yu W, Lou H. Antifungal dibenzofuran bis (bibenzyl) s from the liverwort Asterellaangusta. Phytochemistry. 2007;68:1767-74.

49. Martini U, Zapp J, Becker H. Chlorinated macrocyclic bisbibenzyls from the liverwort Bazzaniatrilobata. Phytochemistry. 1998;47:89-96.

50. Asakawa Y, Toyota M, Uemoto M, Aratani T. Sesquiterpenes of sixPorella species (Hepaticae). Phytochemistry. 1976;15:192931.

51. Guo DX, Xiang F, Wang XN, Yuan HQ, Xi GM, Wang YY, et al. Labdanediterpenoids and highly methoxylatedbibenzyls from the liverwort Frullaniainouei. Phytochemistry. 2010;71:1573-8.

52. Li X, Sun B, Zhu CJ, Yuan HQ, Shi YQ, Gao J, et al. Reversal of p-glycoprotein-mediated multidrug resistance by macrocyclic bisbibenzyl derivatives in adriamycin-resistant human myelogenous leukemia (K562/A02) cells. Toxicol in Vitro. 2009;23:29-36.

53. Li X, Wu WK, Sun B, Cui M, Liu S, Gao J, et al. Dihydroptychantol A, a macrocyclic bisbibenzyl derivative, induces autophagy and following apoptosis associated with p53 pathway in human osteosarcoma U2OS cells. ToxicolApplPharmacol. 2011;251:146-54.

54. Hashimoto T, Kanayama S, Fukuyama Y, Takaoka S, Tori M, Asakawa Y. Two novel macrocyclic bis (bibenzyls), isoplagiochins A and B from the liverwort Plagiochilafruticosa. Tetrahedron Lett. 1994;35:911-2.

55. Xie CF, Qu JB, Wu XZ, Liu N, Ji M, Lou HX. Antifungal macrocyclic bis (bibenzyls) from the Chinese liverwort Ptagiochasmintermedlum L. Nat Prod Res. 2010;24:515-20.

56. Asakawa Y. Terpenoids and aromatic compounds with pharmacological activity from bryophytes. In: Bryophytes: Their chemistry and chemical taxonomy: Clarendon Press; 1990. p. 369-410.

57. Asakawa Y. Highlights in phytochemistry of hepaticaebiologically active terpenoids and aromatic compounds. Pure Appl Chem. 1994;66:2193-6.
58. Asakawa Y. Liverworts-potential source of medicinal compounds. Curr Pharm Des. 2008;14:3067-88.

59. Jensen S, Omarsdottir S, Bwalya AG, Nielsen MA, Tasdemir D, Olafsdottir ES. Marchantin A, a macrocyclic bisbibenzyl ether, isolated from the liverwort Marchantiapolymorpha, inhibits protozoal growth in vitro. Phytomedicine. 2012;19:1191-5.

60. Liu N, Guo DX, Wang YY, Wang LN, Ji M, Lou HX. Aromatic compounds from the liverwort Conocephalumjaponicum. Nat Prod Commun. 2011;6:49-52.

61. Otoguro K, Ishiyama A, Iwatsuki M, Namatame M, NishiharaTukashima A, Kiyohara H, et al. In vitro antitrypanosomal activity of bis (bibenzyls) s and bibenzyls from liverworts against Trypanosoma brucei. J Nat Med. 2012;66:377-82.

62. Asakawa Y. Phytochemistry of bryophytes. In: Phytochemicals in human health protection, nutrition, and plant defense. Boston: Springer; 1999. p. 319-42.

63. Taira Z, Takei M, Endo K, Hashimoto T, Sakiya Y, Asakawa Y. Marchantin A trimethyl ether: its molecular structure and tubocurarine-like skeletal muscle relaxation activity. ChemPharmaceut Bullet. 1994;42:52-6.

64. Schwartner C, Bors W, Michel C, Franck U, Müller-Jakic B, Nenninger A, et al. Effect of marchantins and related compounds on 5-lipoxygenase and cyclooxygenase and their antioxidant properties: a structure activity relationship study. Phytomedicine. 1995;2:113-7.

65. Tanaka M, Esaki T, Kenmoku H, Koeduka T, Kiyoyama Y, Masujima T, et al. Direct evidence of specific localization of sesquiterpenes and marchantin A in oil body cells of Marchantiapolymorpha L. Phytochemistry. 2016;130:77-84.

66. Scher JM, Burgess EJ, Lorimer SD, Perry NB. A cytotoxic sesquiterpene and unprecedented sesquiterpene-bisbibenzyl compounds from the liverwort Schistochilaglaucescens. Tetrahedron. 2002, 2002;58:7875-82.

67. Dey A, Mukherjee A. Therapeutic potential of bryophytes and derived compounds against cancer. J Acute Dis. 2015;4:236-48.

68. Shen J, Li G, Liu Q, He Q, Gu J, Shi Y, et al. Marchantin C: a potential anti-invasion agent in glioma cells. Cancer BiolTher. 2010;9:33-9.

69. Xi GM, Sun B, Jiang HH, Kong F, Yuan HQ, Lou HX. Bisbibenzyl derivatives sensitize vincristine-resistant $\mathrm{KB} / \mathrm{VCR}$ cells to chemotherapeutic agents by retarding P-gp activity. Bioorg Med Chem. 2010;18:6725-33.

70. Lv Y, Song Q, Shao Q, Gao W, Mao H, Lou H, et al. Comparison of the effects of marchantin $\mathrm{C}$ and fucoidan on sFlt-1 and angiogenesis in glioma microenvironment. J Pharm Pharmacol. 2012;64:604-9.

71. Matsunaga Y, Saibara T, Kido H, Katunuma N. Participation of cathepsin B in processing of antigen presentation to MHC class II. FEBS Lett. 1993;324:325-30.

72. Asakawa Y. Biologically active terpenoids and aromatic compounds from liverworts and the inedible mushroom Cryptoporusvolvatus. Bioactive natural products: Detection, isolation, and structural determination. 1993;319.

73. Asakawa Y, Tanikawa K, Aratani T. New substituted bibenzyls of Frullaniabrittoniae subsp. truncatifolia. Phytochemistry. 1976;15: 1057-9.

74. Lou HX, Li GY, Wang FQ. A cytotoxic diterpenoid and antifungal phenolic compounds from Frullaniamuscicola Steph. J Asian Nat Prod Res. 2002;4:87-94.

75. Asakawa Y, Takikawa K, Toyota M, Takemoto T. Novel bibenzyl derivatives and ent-cuparene-type sesquiterpenoids from Radula species. Phytochemistry. 1982;21(10):2481-90.

76. Iwai Y, Murakami K, Gomi Y, Hashimoto T, Asakawa Y, Okuno $\mathrm{Y}$, et al. Anti-influenza activity of marchantins, macrocyclic bisbibenzyls contained in liverworts. PLoS One. 2011;6:e19825. 
77. Xu AH, Hu ZM, Qu JB, Liu SM, Syed AKA, Yuan HQ, et al. Cyclic bisbibenzyls induce growth arrest and apoptosis of human prostate cancer PC3 cells. Acta Pharmacol Sin. 2010;31:609.

78. Asakawa Y. Biologically active compounds from bryophytes. The Journal of the Hattori Botanical Laboratory. 1998;84:91-104.

79. Toyota M, Tori M, Takikawa K, Shiobara Y, Kodama M, Asakawa Y. Perrottetins E, F, and G from Radula perrottetii (liverwort)-isolation, structure determination, and synthesis of perrottetin e. Tetrahedron Lett. 1985;26:6097-100

80. Asakawa Y, Kondo K, Takikawa NK, Tori M, Hashimoto T, Ogawa S. Prenylbibenzyls from the liverwort Radula kojana. Phytochemistry. 1991;30:219-34.

81. Nagashima F, Momosaki S, Watanabe Y, Toyota M, Huneck S, Asakawa Y. Terpenoids and aromatic compounds from six liverworts. Phytochemistry. 1996;41:207-11.

82. Fukuyama Y, Yaso H, Nakamura K, Kodama M. Total synthesis of Plagiochin D, a macrocyclic bis (bibenzyl) from liverworts by intramolecular Still-Kelly reaction. Tetrahedron Lett. 1999;40(1): $105-8$.

83. Wu XZ, Chang WQ, Cheng AX, Sun LM, Lou HX. Plagiochin E, an antifungal active macrocyclic bis (bibenzyl), induced apoptosis in Candida albicans through a metacaspase-dependent apoptotic pathway. BiochimicaetBiophysicaActa (BBA)-General Subjects. 2010;1800:439-47.

84. Wu XZ, Cheng AX, Sun LM, Sun SJ, Lou HX. Plagiochin E, an antifungal bis (bibenzyl), exerts its antifungal activity through mitochondrial dysfunction-induced reactive oxygen species accumulation in Candida albicans. BiochimicaetBiophysicaActa (BBA)General Subjects. 2009;1790:770-7.

85. Yoshida T, Hashimoto T, Takaoka S, Kan Y, Tori M, Asakawa Y, et al. Phenolic constituents of the liverwort: four novel cyclic bisbibenzyl dimers from BlasiapusillaL. Tetrahedron Lett. 1996;52:14487-500.

86. Keseru GM, Nógrádi M. The biological activity of cyclic bis (bibenzyls): a rational approach. Bioorg Med Chem. 1995a;3: 1511-7.

87. Keseru GM, Nógrádi M. The chemistry of macrocyclic bisbibenzyls. Nat Prod Rep. 1995b;12:69-75.

88. Shi YQ, Qu XJ, Liao YX, Xie CF, Cheng YN, Li S, et al. Reversal effect of a macrocyclic bisbibenzylplagiochin $\mathrm{E}$ on multidrug resistance in adriamycin-resistant K562/A02 cells. Eur J Pharmacol. 2008;584:66-71.

89. Sun CC, Zhang YS, Xue X, Cheng YN, Liu HP, Zhao CR, et al. Inhibition of angiogenesis involves in anticancer activity of riccardin $\mathrm{D}$, a macrocyclic bisbibenzyl, in human lung carcinoma. Eur J Pharmacol. 2011;667:136-43.

90. Xue X, Qu XJ, Gao ZH, Sun CC, Liu HP, Zhao CR, et al. Riccardin D, a novel macrocyclic bisbibenzyl, induces apoptosis of human leukemia cells by targeting DNA topoisomerase II. Investig New Drugs. 2012;30:212-22.

91. Li Y, Ma Y, Zhang L, Guo F, Ren L, Yang R, et al. In vivo inhibitory effect on the biofilm formation of Candida albicans by liverwort derived riccardin D. PLoS One. 2012;7:e35543.

92. Liu HP, Gao ZH, Cui SX, Sun DF, Wang Y, Zhao CR, et al. Inhibition of intestinal adenoma formation in APCmin/+ mice by riccardin $\mathrm{D}$, a natural product derived from liverwort plant Dumortierahirsuta. PLoS One. 2012;7:e33243.

93. Ji M, Shi Y, Lou H. Overcoming of P-glycoprotein-mediated multidrug resistance in K562/A02 cells using riccardin $\mathrm{F}$ and pakyonol, bisbibenzyl derivatives from liverworts. Biosci Trends. 2011;5:192-7.

94. Baek SH, Phipps RK, Perry NB. Antimicrobial Chlorinated Bibenzyls from the Liverwort Riccardiamarginata. J Nat Prod. 2004:67:718-20.
95. Lorimer SD, Barns G, Evans AC, Foster LM, May BC, Perry NB, et al. Cytotoxicity and antimicrobial activity of plants from New Zealand's subantarctic islands. Phytomedicine. 1996;2:317-23.

96. Sadamori M. Studies on the new biologically active substances of Tahitian and Tokushima's Plagiochila genus (Doctoral dissertation, Master thesis, Tokushima Bunri University, Tokushima, Japan).

97. Lorimer SD, Perry NB. Antifungal hydroxy-acetophenones from the New Zealand liverwort, Plagiochilafasciculata. Planta Med. 1994;60:386-7.

98. Emmens CW, Collins DJ, Hobbs JJ, Miller BG, Owen WH. Antioestrogenic and antifertility properties of some 4, 4'dihydroxybibenzyls. Reproduction. 1968;16:1-6.

99. Toyota M, Shimamura T, Ishii H, Renner M, Braggins J, Asakawa Y. New bibenzyl cannabinoid from the New Zealand liverwort Radula marginata. ChemPharmaceut Bull. 2002;50:1390-2.

100. Cullmann F, Becker H, Pandolfi E, Roeckner E, Eicher T. Bibenzyl derivatives from Pelliaepiphylla. Phytochemistry. 1997;45:1235-47.

101. Hanuš LO, Meyer SM, Muñoz E, Taglialatela-Scafati O, Appendino G. Phytocannabinoids: a unified critical inventory. Nat Prod Rep. 2016;33:1357-92.

102. Park BH, Lee YR. Concise synthesis of $( \pm)$-perrottetinene with bibenzyl cannabinoid. Bull Kor Chem Soc. 2010;31:2712-4.

103. Hussain T, Espley RV, Gertsch J, Whare T, Stehle F, Kayser O. Demystifying the liverwort Radula marginata, a critical review on its taxonomy, genetics, cannabinoid phytochemistry and pharmacology. Phytochem Rev. 2019;18:953-65.

104. Wang X, Li L, Zhu R, Zhang J, Zhou J, Lou H. Bibenzyl-based meroterpenoid enantiomers from the Chinese liverwort Radula sumatrana. J Nat Prod. 2017;80:3143-50.

105. Chicca A, Schafroth MA, Reynoso-Moreno I, Erni R, Petrucci V, Carreira EM, et al. Uncovering the psychoactivity of a cannabinoid from liverworts associated with a legal high. Sci Adv. 2018;4:e2166.

106. Mendizabal VE, Adler-Graschinsky E. Cannabinoids as therapeutic agents in cardiovascular disease: a tale of passions and illusions. Br J Pharmacol. 2007;151:427-40.

107. Degenhardt L, Hall WD. The adverse effects of cannabinoids: implications for use of medical marijuana. Cmaj. 2008;178: 1685-6.

108. Schachtsiek J, Warzecha H, Kayser O, Stehle F. Current perspectives on biotechnological cannabinoid production in plants. Planta Med. 2018;84:214-20.

109. Chen XJ, Mei WL, Cai CH, Guo ZK, Song XQ, Dai HF. Four new bibenzyl derivatives from Dendrobium sinense. Phytochem Lett. 2014;9:107-12.

110. Wang L, Zhang CF, Wang ZT, Zhang M, Xu LS. Five new compounds from Dendrobium crystallinum. J Asian Nat Prod Res. 2009;11:903-11.

111. Zhan R, Zhang Y, Chen L, Chen Y. A new (propylphenyl) bibenzyl from Eriabambusifolia. Nat Prod Res. 2016;30:1740-5.

112. Zhang GN, Zhong LY, Bligh SA, Guo YL, Zhang CF, Zhang M, et al. Bi-bicyclic and bi-tricyclic compounds from Dendrobium thyrsiflorum. Phytochemistry. 2005;66:1113-20.

113. Li Y, Wang CL, Wang YJ, Guo SX, Yang JS, Chen XM, et al. Three new bibenzyl derivatives from Dendrobium candidum. ChemPharmaceut Bull. 2009;57:218-9.

114. Li YP, Wang YJ, Chen LL. Antioxidant bibenzyls, phenanthrenes, and fluorenones from Dendrobium chrysanthum. Chem Nat Compd. 2016;52:90-2.

115. Kongkatitham V, Muangnoi C, Kyokong N, Thaweesest W, Likhitwitayawuid K, Rojsitthisak P, et al. Anti-oxidant and antiinflammatory effects of new bibenzyl derivatives from Dendrobium parishii in hydrogen peroxide and lipopolysaccharide treated RAW264. 7 cells. PhytochemLett. 2018;24:31-8. 
116. Jia F, Xia HL, Ning ZJ, Huang P, Huang XY, Tang JJ, et al. In vitro antioxidant activity of bibenzyl compounds from Dendrobinmdenneanum. SciTechnol Food Industr. 2014;7:15.

117. Beacock CJ, Buck AC, Roberts EE. Bifluranol in the treatment of benign prostatic hyperplasia (BPH). Prostate. 1985;7:357-61.

118. Chao WH, Lai MY, Pan HT, Shiu HW, Chen MM, Chao HM. Dendrobium nobile Lindley and its bibenzyl component moscatilin are able to protect retinal cells from ischemia/hypoxia by dowregulating placental growth factor and upregulating Norrie disease protein. BMC Complement Altern Med. 2018;18:193.

119. Majumder PL, Guha S, Sen S. Bibenzyl derivatives from the orchid Dendrobium amoenum. Phytochemistry. 1999;52:1365-9.

120. Majumder PL, Pal S. Cumulatin and tristin, two bibenzyl derivatives from the orchids Dendrobium cumulatum and Bulbophyllum triste. Phytochemistry. 1993.

121. Majumder PL, Chatterjee S. Crepidatin, a bibenzyl derivative from the orchid Dendrobium crepidatum. Phytochemistry. 1989;28:1986-8.

122. Majumder PL, Roychowdhury M, Chakraborty S. Bibenzyl derivatives from the orchid Bulbophyllumprotractum. Phytochemistry. 1997;44:167-72.

123. Wu B, Chen J, He S, Pan Y. Oxepine and bibenzyl compounds from Bulbophyllumkwangtungense. Chem J Chinese UnivChinese edition. 2008;29:305.

124. Oiso Y, Toyota M, Asakawa Y. Occurrence of a bis-bibenzyl derivative in the Japanese fern Hymenophyllumbarbatum: first isolation and identification of perrottetinH from the pteridophytes. ChemPharmaceut Bull-Tokyo. 1999;47:297-8.

125. Harinantenaina L, Quang DN, Takeshi N, Hashimoto T, Kohchi C, Soma GI, et al. Bis (bibenzyls) from Liverworts Inhibit Lipopolysaccharide-Induced Inducible NOS in RAW 264.7 Cells: A Study of Structure- Activity Relationships and Molecular Mechanism. J Nat Prod. 2005;68:1779-81.

126. Keseru GM, Nógrádi M. Molecular similarity analysis on biologically active macrocyclic bisbibenzyls. J MolRecogn. 1996;92:133-8.

127. Gorham J. Lunularic acid and related compounds in liverworts, algae and Hydrangea. Phytochemistry. 1977, 1977;16:249-53.

128. Asakawa Y. Chemical relationships between algae, bryophytes and pteridophytes. J Bryol. 1986;14:59-70.

129. Pryce R. The occurrence of lunularic and abscisic acids in plants. Phytochemistry. 1972;11:1759-61.

130. Glombitza KW. In: Hoppe HA, Levring T, Tanaka Y, editors. Marine algae in pharmaceutical science. Berlin: WaIter de Gruyter; 1979. p. 303-42.

131. Allegrone G, Pollastro F, Magagnini G, Taglialatela-Scafati O, Seegers J, Koeberle A, et al. The bibenzylcanniprene inhibits the production of pro-inflammatory eicosanoids and selectively accumulates in some Cannabis sativa strains. J Nat Prod. 2017;80:731-4.

132. Huang JY, Yuan YH, Yan JQ, Wang YN, Chu SF, Zhu CG, et al. 20C, a bibenzyl compound isolated from Gastrodiaelata, protects PC12 cells against rotenone-induced apoptosis via activation of the Nrf2/ARE/HO-1 signaling pathway. ActaPharmacolog Sin. 2016;37:731.

133. Mou Z, Yuan YH, Lou YX, Heng Y, Huang JY, Xia CY, et al. Bibenzyl compound 20c protects against endoplasmic reticulum stress in tunicamycin-treated PC12 cells in vitro. ActaPharmacolog Sin. 2016;37(12):1525.

134. Zhang $\mathrm{X}, \mathrm{Xu} \mathrm{JK}$, Wang J, Wang NL, Kurihara H, Kitanaka S, et al. Bioactive bibenzyl derivatives and fluorenones from Dendrobium nobile. J Nat Prod. 2007;70:24-8.

135. Harris ES. Ethnobryology: traditional uses and folk classification of bryophytes. Bryologist. 2008;111:169-218.

136. Mondal AK, Mondal S. Ethnobryology-Seeking More Deserving Future. Front Biol. 2009:37-42.

137. Sabovljević MS, Sabovljević AD, Ikram NK, Peramuna A, Bae H, Simonsen HT. Bryophytes-an emerging source for herbal remedies and chemical production. Plant genetic resources. 2016;14(4):314-27.

138. Gibbons S. Anti-staphylococcal plant natural products. Nat Prod Rep. 2004;21:263-77.

139. Asakawa Y. Fortschritte der Chemie organischer Naturstoffe/ Progress in the Chemistry of Organic Natural Products. Springer Science \& Business Media; 2012.

140. Zhao C, Lou Z, Guo Y, Ma M, Chen Y, Liang S, et al. Nucleoside monophosphate complex structures of the endonuclease domain from the influenza virus polymerase PA subunit reveal the substrate binding site inside the catalytic center. J Virol. 2009;83:9024-30.

141. Morris GM, Goodsell DS, Halliday RS, Huey R, Hart WE, Belew RK, et al. Automated docking using a Lamarckian genetic algorithm and an empirical binding free energy function. J Comput Chem. 1998;19:1639-62.

142. Taub M, Saier MH Jr. An established but differentiated kidney epithelial cell line (MDCK). Methods Enzymol. 1979;58:552-60 Academic Press.

143. Goto J, Kataoka R, Muta H, Hirayama N. ASEDock-docking based on alpha spheres and excluded volumes. J Chem Inf Model. 2008;48:583-90.

144. Okuno YO, Tanaka KE, Baba KO, Maeda AK, Kunita NO, Ueda S. Rapid focus reduction neutralization test of influenza A and B viruses in microtiter system. J Clin Microbiol. 1990;28:1308-13.

145. Thompson JD, Gibson TJ, Plewniak F, Jeanmougin F, Higgins DG. The CLUSTAL_X windows interface: flexible strategies for multiple sequence alignment aided by quality analysis tools. Nucleic Acids Res. 1997;25:4876-82.

146. Yang CS, Wang X, Lu G, Picinich SC. Cancer prevention by tea: animal studies, molecular mechanisms and human relevance. Nat Rev Cancer. 2009;9:429.

147. Dias A, Bouvier D, Crépin T, McCarthy AA, Hart DJ, Baudin F, et al. The cap-snatching endonuclease of influenza virus polymerase resides in the PA subunit. Nature. 2009;458:914.

148. Yuan P, Bartlam M, Lou Z, Chen S, Zhou J, He X, et al. Crystal structure of an avian influenza polymerase PA N reveals an endonuclease active site. Nature. 2009;458:909.

149. Sawada H, Onoda K, Morita D, Ishitsubo E, Matsuno K, Tokiwa H, et al. Structure-anti-MRSA activity relationship of macrocyclic bis (bibenzyl) derivatives. Bioorg Med Chem Lett. 2013;23:6563-8.

150. Dekanski JB. Anti-prostatic activity of bifluranol, a fluorinated bibenzyl. Br J Pharmacol. 1980;71:11.

151. Fujii K, Morita D, Onoda K, Kuroda T, Miyachi H. Minimum structural requirements for cell membrane leakage-mediated antiMRSA activity of macrocyclic bis (bibenzyl) s. Bioorg Med Chem Lett. 2016;26:2324-7.

152. Onoda K, Sawada H, Morita D, Fujii K, Tokiwa H, Kuroda T, et al. Anti-MRSA activity of isoplagiochin-type macrocyclic bis (bibenzyl) $\mathrm{s}$ is mediated through cell membrane damage. Bioorg Med Chem. 2015;23:3309-16.

153. Tulp M, Bohlin L. Functional versus chemical diversity: is biodiversity important for drug discovery? Trends Pharmacol Sci. 2002;23:225-31.

154. Spörle J, Becker H, Allen NS, Gupta MP. Spiroterpenoids from Plagiochila moritziana. Phytochemistry. 1991;30:3043-7.

155. Oozeki H, Tajima R, Nihei KI. Molecular design of potent tyrosinase inhibitors having the bibenzyl skeleton. Bioorg Med Chem Lett. 2008;18:5252-4.

156. Tajima R, Oozeki H, Muraoka S, Tanaka S, Motegi Y, Nihei H, et al. Synthesis and evaluation of bibenzyl glycosides as potent tyrosinase inhibitors. Eur J Med Chem. 2011;46:1374-81.

157. Clere N, Faure S, Helesbeux JJ, Duval O, Andriantsitohaina R. Paradoxical effects of ethoxidine, a topoisomerase I inhibitor, in the cellular processes leading to angiogenesis on endothelial cells. Carcinogenesis. 2010;32:286-95. 
158. Skarlos DV, Bai M, Goussia A, Samantas E, Galani E, Tsavdaridis $\mathrm{D}$, et al. Expression of a molecular marker panel as a prognostic tool in gastric cancer patients treated postoperatively with docetaxel and irinotecan. A study of the Hellenic Cooperative Oncology Group. Anticancer Res. 2007;27:2973-83.

159. Tsakonas G, Kosmas C. Integration of novel targeted therapies into the systemic treatment of breast. J BUON. 2007;12:319-27.

160. Tang L, Ma X, Tian Q, Cheng Y, Yao H, Liu Z, et al. Inhibition of angiogenesis and invasion by DMBT is mediated by downregulation of VEGF and MMP-9 through Akt pathway in MDA-MB231 breast cancer cells. Food Chem Toxicol. 2013;56:204-13.

161. Song JX, Shaw PC, Sze CW, Tong Y, Yao XS, Ng TB, et al. Chrysotoxine, a novel bibenzyl compound, inhibits 6hydroxydopamine induced apoptosis in SH-SY5Y cells via mitochondria protection and NF- $\mathrm{KB}$ modulation. Neurochem Int. 2010;57:676-89.

162. Gottesman MM. Mechanisms of cancer drug resistance. Ann Rev Med. 2002;53:615-27.

163. Sharma C, Sadek B, Goyal SN, Sinha S, Kamal MA, Ojha S. Small molecules from nature targeting G-protein coupled cannabinoid receptors: potential leads for drug discovery and development. Evid-Based Comp Altern Med. 2015;2015.

164. Harrowven DC, Kostiuk SL. Macrocylic bisbibenzyl natural products and their chemical synthesis. Nat Prod Rep. 2012;29:223-42.

165. Asakawa Y. In: Herz W, Grisebach H, Kirby GW, editors. Progress in the Chemistry of Organic Natural Products. Chemical constituents of Hepaticae, vol. 42. Wien: Springer; 1982. p. 1-285.

166. Asakawa Y. Biologically active compounds from bryophytes. Pure Appl Chem. 2007;79:557-80.

167. Asakawa Y. Biologically active terpenoids and aromatic compounds from liverworts and the inedible mushroom Cryptoporus volvatus. Bioactive natural products: Detection, isolation, and structural determination 1993;319.

168. Thangavel G, Nayar S. A survey of MIKC type MADS-box genes in non-seed plants: algae, bryophytes, lycophytes and ferns. Front Plant Sci. 2018;9:510.

169. Coxson DS. Nutrient release from epiphytic bryophytes in tropical montane rain forest (Guadeloupe). Can J Bot. 1991;69:2122-9.

170. Peters K, Gorzolka K, Bruelheide H, Neumann S. Computational workflow to study the seasonal variation of secondary metabolites in nine different bryophytes. Sci data. 2018;5:180179.

171. Miller NG. Modern research with bryophytes: an overview. Memoirs of the Torrey Botanical Club. 1993:1-10.

172. Ghani NA, Ismail NH, Noma Y, Asakawa Y. Microbial transformation of some natural and synthetic aromatic compounds by fungi: Aspergillus and Neurospora strains. Nat Prod Commun. 2017;12:1934578X1701200822.

173. Sabovljević MS, Vujičić M, Wang X, Garraffo HM, Bewley CA, Sabovljević A. Production of the macrocyclic bis-bibenzyls in axenically farmed and wild liverwort Marchantiapolymorpha L. subsp. ruderalisBischl. etBoisselier. Plant Biosystems-An International Journal Dealing with all Aspects of Plant Biology. 2017;151:414-8.

174. Schmidt RJ. Allergic contact dermatitis to liverworts, lichens, and mosses. In Semin Dermatol 1996 (Vol. 15, No. 2, pp. 95-102). [New York, NY]: Thieme-Stratton,[c1982]-c1996.

175. Schultz TP, Boldin WD, Fisher TH, Nicholas DD, McMurtrey KD, Pobanz K. Structure-fungicidal properties of some 3-and 4hydroxylated stilbenes and bibenzyl analogues. Phytochemistry. 1992;31:3801-6.

176. Asakawa Y, Matsuda R, Cheminat A. Bibenzyl derivatives from Frullania species. Phytochemistry. 1987;26:1117-22.

177. Fan S, Zhu R, Zhou J, Li Y, Qiao Y, Zhang C, et al. Prenylbibenzyls isolated from Chinese liverwort Radula amoena and their cytotoxic activities. Phytochem Lett. 2019;31:53-7.
178. Hsiao G, Teng CM, Wu CL, Ko FN. Marchantin H as a natural antioxidant and free radical scavenger. Arch Biochem Biophys. 1996;334:18-26.

179. Yang MH, Fang YS, Cai L, Li Y, Dong JW, Yin TP, et al. A new flavone C-glycoside and a new bibenzyl from Bulbophyllum retusiusculum. Nat Prod Res. 2016;30(14):1617-22.

180. Bhummaphan N, Pongrakhananon V, Sritularak B, Chanvorachote P. Cancer Stem Cell-Suppressing Activity of Chrysotoxine, a Bibenzyl from Dendrobium pulchellum. J Pharmacol Exp Ther. 2018;364:332-46.

181. Mittraphab A, Muangnoi C, Likhitwitayawuid K, Rojsitthisak P, Sritularak B. A new bibenzyl-phenanthrene derivative from Dendrobium signatum and its cytotoxic activity. Nat Prod Commun. 2016;11:1934578X1601100526.

182. Yang M, Zhang Y, Chen L, Chen Y. A new (propylphenyl) bibenzyl derivative from Dendrobium williamsonii. Nat Prod Res. 2018;32:1699-705.

183. Cretton S, Oyarzún A, Righi D, Sahib L, Kaiser M, Christen P, et al. A new antifungal and antiprotozoal bibenzyl derivative from Gavilea lutea. Nat Prod Res. 2018;32:695-701.

184. Charoenrungruang S, Chanvorachote P, Sritularak B, Pongrakhananon V. Gigantol, a bibenzyl from Dendrobium draconis, inhibits the migratory behavior of non-small cell lung cancer cells. J Nat Prod. 2014;77:1359-66.

185. Miyazawa M, Shimamura H, Nakamura SI, Kameoka H. Antimutagenic activity of gigantol from Dendrobium nobile. J Agric Food Chem. 1997;45:2849-53.

186. Ho CK, Chen CC. Moscatilin from the orchid Dendrobrium loddigesii is a potential anticancer agent. Cancer Investig. 2003;21:729-36.

187. Tsai AC, Pan SL, Liao CH, Guh JH, Wang SW, Sun HL, et al. Moscatilin, a bibenzyl derivative from the India orchid Dendrobrium loddigesii, suppresses tumor angiogenesis and growth in vitro and in vivo. Cancer Lett. 2010;292:163-70.

188. Hernández-Romero Y, Acevedo L, de Los Ángeles Sánchez M, Shier WT, Abbas HK, Mata R. Phytotoxic activity of bibenzyl derivatives from the orchid Epidendrum rigidum. J Agric Food Chem. 2005;53:6276-80.

189. Lee KY, Jeong EJ, Sung SH, Kim YC. Stemona alkaloids isolated from Stemona tuberosa roots and their inhibitory activity on lipopolysaccharide-induced nitric oxide production. Rec Nat Prod. 2016;10:109.

190. Zhang ZC, Su G, Li J, Wu H, Xie XD. Two new neuroprotective phenolic compounds from Gastrodia elata. J Asian Nat Prod Res. 2013;15:619-23.

191. Chaotham C, Pongrakhananon V, Sritularak B, Chanvorachote P. A Bibenzyl from Dendrobium ellipsophyllum inhibits epithelialto-mesenchymal transition and sensitizes lung cancer cells to anoikis. Anticancer Res. 2014;34:1931-8.

192. Chaotham C, Chanvorachote P. A bibenzyl from Dendrobium ellipsophyllum inhibits migration in lung cancer cells. J Nat Med. 2015;69:565-74.

193. Sritularak B, Duangrak N, Likhitwitayawuid K. A new bibenzyl from Dendrobium secundum. Zeitschrift für Naturforschung C. 2011;6:205-8.

194. Liu YC, Liu G, Zhang XM, Chen JC, Qiu MH, Qiu DW. New Bibenzyl Derivative from Miao Medicine Herminium bulleyi. Chem J Chin Univ. 2012;18.

195. Wu B, He S, Pan YJ. New dihydrodibenzoxepins from Bulbophyllum kwangtungense. Planta Med. 2006;72:1244-7.

Publisher's note Springer Nature remains neutral with regard to jurisdictional claims in published maps and institutional affiliations. 